\title{
Thermal fluid circulation around the Karliova triple junction: Geochemical features and volcano-tectonic implications (Eastern Turkey)
}

\author{
Özgür Karaoğlu ${ }^{\mathrm{a}, *}$, Mohsen Bazargan ${ }^{\mathrm{b}, \mathrm{c}}$, Alper Baba ${ }^{\mathrm{d}}$, John Browning ${ }^{\mathrm{e}}$ \\ ${ }^{a}$ Eskişehir Osmangazi University, Department of Geological Engineering, 26040, Eskişehir, Turkey \\ ${ }^{\mathrm{b}}$ Department of Earth Sciences, Royal Holloway University of London, Egham, TW20 OEX, UK

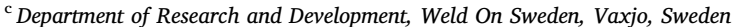 \\ d Izmir Institute of Technology, Engineering Faculty, 35430, Urla, Izmir, Turkey \\ ${ }^{\mathrm{e}}$ Department of Mining Engineering and Department of Structural and Geotechnical Engineering, Pontificia Universidad Católica de Chile, Santiago, Chile
}

A R T I C L E I N F O

\section{Keywords:}

Fluid circulation

Thermal water

Karliova triple junction

Caldera

Tectonic

\begin{abstract}
A B S T R A C T
The Karlıova triple junction (KTJ) in eastern Turkey has been subjected to incremental deformation resulting in complex kinematic and mechanical interactions throughout the upper crust. These interactions have generated tectonic inversions and uplift, extensive seismicity and volcanism. The regional tectonics generate local stresses, some of which are favorable to magma transport and thermal water circulation throughout the lithosphere. Here we evalauate hydrogeochemical, geological and numerical results relating to the mechanism of thermal fluid circulation around the KTJ. Hydrogeochemistry of the samples indicates that the thermal water springs are probably heated by steam. Volcanic rocks at the site appear to be the host rock owing to the enrichment of $\mathrm{Na}^{+}$ and $\mathrm{Cl}^{-}$ions in water and the abundance of these elements in minerals of the volcanic rocks. In addition, it is clear that the thermal fluids are sourced from depth and migrate through permeable networks of faults. The effects of crustal heterogeneities, in particular the geometry and mechanical properties of many faults and layers, on thermal fluid circulation in relation to active magma chambers were investigated under a variety of different mechanical conditions. The numerical results indicate very close relationships between the stress field causing faulting and thermal fluid movement in the KTJ. The effect of thermal transfer was modeled with depth throughout the crust and along the the crustal surface. The models show that some faults encourage thermal fluid circulation below the Varto and Özenç volcanoes. Hydrogeochemical, geological and numerical results suggest that magmas residing beneath both the Varto caldera and the Özenç volcano are the main heat source for thermal fluid in the Varto region. Fluid-solid interactions and fluid circulation models show that the permeable faults are important factors affecting heat transport and fluid circulation. In a series of thermal fluid flow models we probe the mechanism for fluid and gas transport from the $900{ }^{\circ} \mathrm{C}$ 'hot' zone around the deep magma chambers and investigate how heat is lost throughout the crust on the way to the surface and so eventually creates water channels of temperatures between 50 to $60{ }^{\circ} \mathrm{C}$.
\end{abstract}

\section{Introduction}

Faults and fractures which accommodate the deformation of large sections of the upper crust have a significant impact on the physical processes controlling heat transfer and fluid motion in the subsurface. This is because they disturb the conformal succession of geological layers (Press and Siever, 1995). In addition, the mechanical properties of the rocks, the hydraulic characteristics of the rocks, and the geologic and also geodynamic relations provide useful information about thermal fluid circulation through the fractured upper crust. Numerical modeling provides one approach to estimate the structural setting of the subsurface and the mechanical processes controlling fluid and heat transfer (e.g., Cherubini et al., 2013).

The emplacement of hot asthenospheric mantle into shallow levels beneath the crustal materials of the Karliova-type triple junction could be expected to generate magmatism and possibly thermal water potential. Consistent with this expectation, sequences of volcanic centers have historically erupted along the triple junction within Karlıova (e.g., Furlong and Schwartz, 2004).

Geothermal systems are linked to magmatism in a variety of geodynamic contexts in volcanic environments (i.e., island arcs, hot-spots, middle oceanic ridges, sea-mounts, intraplate volcanism and intrusions)

\footnotetext{
* Corresponding author.

E-mail address: ozgur.karaoglu@deu.edu.tr (Ö. Karaoğlu).
} 
(Caracausi et al., 2005). Thermal fluid circulation is affected by both temporal variations in degassing and in the activity level of the magmatic systems supplying fluids and energy to the geothermal reservoirs (Baker, 1995; Von Damm et al., 1995; Baker and Urabe, 1996; Giggenbach, 1996; Caracausi et al., 2005). Active tectonics and very recent volcanic activity have a strong impact on the geochemistry of the circulating fluids (e.g., Italiano et al., 2013).

A triple junction that deforms the upper crust in a complex manner is a site of special interest in which to study thermal and cold water transportation. Geometric consequences of the motions of three plates, following a collision between convergent plates, mostly result in extrusion through crustal-scale transtensive faults. Triple junction tectonics can produce surface uplift and crustal deformation, abundant seismic activity, high heat flow, and the eruption of volcanoes on the Earth's surface (e.g., Furlong and Schwartz, 2004).

In order to better understand the source and thermo-mechanical constraints on hydrothermal systems, the detailed geologic background and geochemical analysis of the fluids, which in turn form a numerical modeling approach, must first be evaluated. The young Karliova-Varto volcanic terrain provides an excellent opportunity to explore the relationships between magmatic heat sources (i.e., magma chambers, magma storage, magma plumes, hot spots) and geothermal fluids throughout the upper crust.

The aim of the study is to demonstrate how hydrothermal systems follow paths with different dimensions along these faults, and also how a fluid behaves in this intensely deformed crust. The hydrogeochemistry of geothermal springs around the Varto volcanic province is documented in order to link geochemical constraints with thermomechanical controls on fluids in the crust.

\section{Tectonic and geologic setting}

Eastern Turkey represents a particular part of the Mediterranean region which is characterized by the presence of major continental fragments and suture zones (e.g., Isik et al., 2014). The closure of the Neotethyan Ocean along the BZSZ during the Cretaceous-early Paleogene led to the formation of the Eastern Anatolian Accretionary Complex (EAAC), which has subsequently acted as one of the major tectonic units during the subsequent tectonic evolution of the region (Barka, 1992; Okay and Tüysüz, 1999; Bozkurt, 2001).

The Karliova triple junction area is one of the best examples of an active continental collision zone in the world (Fig. 1). The location, timing and geochemical characteristics of volcanism result from the complex interaction of the colliding Eurasian and Afro-Arabian plates. Escape tectonics of the Anatolian plate to the west gave rise to strikeslip motion along the North Anatolian Fault Zone (NAFZ) and East Anatolian Fault Zone (EAFZ) after the closure of the Neotethyan Ocean as a result of Arabia-Eurasian convergence (Barka, 1992; Okay and Tüysüz, 1999; Bozkurt, 2001). The Varto Fault Zone (VFZ) presents a structural continuation of the NAFZ starting from the KTJ (Fig. 2). The VFZ is composed of sets of discontinuous faults with differential kinematics and associated sets of striae (Karaoğlu et al., 2017). The VFZ extends for over $50 \mathrm{~km}$ and can be subdivided into six segments (Fig. 1b). Fault planes from the VFZ commonly exhibit multiple sets of striations, highlighting incremental and complex deformation of the KTJ region since 6 Ma (Karaoğlu et al., 2017).

The northernmost segment of the VFZ, called the Tuzla Fault, is mainly a thrust fault (Karaoğlu et al., 2017). The western part of these faults is offset laterally by the EAFZ (Fig. 1b). The Varto fault is the most seismically active segment of the VFZ, a N70 ${ }^{\circ} \mathrm{W}$-trending-normal fault that offsets the southern part of the Varto caldera (Fig. 1b) (or the Bingöl caldera; Hubert-Ferrari et al., 2009), and was introduced for the first time by Karaoğlu et al. (2017). Several destructive earthquakes $(\mathrm{Mw}=6.8)$ shifting further south took place on the Varto fault in 1966 and on the Leylek Fault $(\mathrm{Mw}=6.2)$, and there was also a small earthquake $(\mathrm{Mw} \geq 3)$ on the Çayçatı Fault (Wallace, 1968; Ambraseys and Zatopek, 1968).

The first volcanic activity began with high-silica obsidian flows at Çatak on the EAFZ reflecting the southern branch of the triple junction, and started at $6.06 \mathrm{Ma}$ (Poidevin, 1998). Two composite volcanoes were emplaced in the area at around $3 \mathrm{My}$ ago. The Turnadağ volcano located in the western part of KTJ was formed 2.3-2.8 Ma ago, but the Varto caldera was active 2.6-3.1 Ma ago (Fig. 2) (see Pearce et al., 1990; Hubert-Ferrari et al., 2009 for details about K/Ar whole rock and ${ }^{40} \mathrm{Ar} /{ }^{39} \mathrm{Ar}$ groundmass dating of the rocks). The two volcanic domes are $0.46 \mathrm{Ma}$ and 0.73 Ma old (Hubert-Ferrari et al., 2009, see Fig. 2). Recent tomographic image data shows the presence of active magma reservoirs throughout the crust around the Karlıova region (Salah et al., 2011; Karaoğlu et al., 2018).

The Varto and Turnadağ volcanoes exhibit quite similar major or trace element compositions. Volcanic rocks from the two volcanoes are composed of high-K and shoshonitic series rocks including trachy-andesite to rhyolite with a small amount of basaltic trachy-andesite (Buket and Temel, 1998; Hubert-Ferrari et al., 2009).

Italiano et al. (2013) stated that the release of volcanic fluids is a common feature along the main active faults in Turkey, however the local geological setting is responsible for the uprising of deep fluids through tectonic discontinuities and the occurrence of shallow processes affecting the original characteristics of the circulating fluids. Moreover, the presence of carbonatic rocks, travertine deposits, metamorphic rocks and old volcanic rocks (Fig. 2) accounts for the different nature of the circulating fluids and different fluid-rock interactions (Italiano et al., 2013). Across the Karlıova-Varto area, a volcano-sedimentary package, around $45 \mathrm{~m}$ thick, interfingers with the effusive and explosive-type volcanic rocks of the Bingöl group (Fig. 2). The former volcano-sedimentary deposits display a well preserved subaqueoussubaerial transition in a fluvio-lacustrine setting generated after some volcanic eruptions. The deposits are composed of mud-poor sandstone, sand-filled pebbles intercalated with the mudstone, which in turn are exposed in restricted plains dissected by braided rivers in the western part of the Varto caldera (Karaoğlu et al., 2017). Most of these volcaniclastic successions have experienced an intense deformation particularly since 6 Ma. These deposits are overlain by lava stacks and ignimbrite veneers of the Varto group. The Pleistocene lacustrine sediments are mainly composed of marl, limestone, and tuff. Tectonic activity has created a faint deformation within these deposits on the plain near Teknedüzü and Yayıklı villages (Fig. 2). Fault complexity is observed in strongly folded lacustrine sediments at a meter-scale, with nearly horizontal axial planes, whose strikes are scattered around an NNE-SSW direction (Fig. 1b). The youngest effusive and extrusive volcanism conformably overlies these sediments. A massive-type travertine is exposed in the northern part of Karliova, on a continuation of the EAF to the northeast.

\section{Fault kinematics}

KTJ is a key area for understanding the deformation of Neogene volcanoes in eastern Turkey because of their progressive inversion tectonics. Structural analysis suggests that this volcano has undergone incremental tectonic controls in eastern Turkey since the Upper Miocene. Karaoğlu et al. (2017) documented 128-slip data points from 16 locations of two transpressional and transtensional deformational fields which were collected for palaeostress analysis (Fig. 3). The fault surfaces document that inversion tectonics dominated the area when both extensional and transtensional deformational phases progresively reversed over the past 3 My (Karaoğlu et al., 2017). Structural data across the Varto Fault Zone (VFZ), obtained from six faults for which kinematics indicate a range of shortening and extensional deformation for $3 \mathrm{Ma}$ (Fig. 3). Many fault surfaces show evidence of reactivation. Particularly, the splays of the VFZ and the other segmented faults have thrust to strike-slip fault components, indicating multiple reactivation events. To establish the surface expressions of the deformation process, 

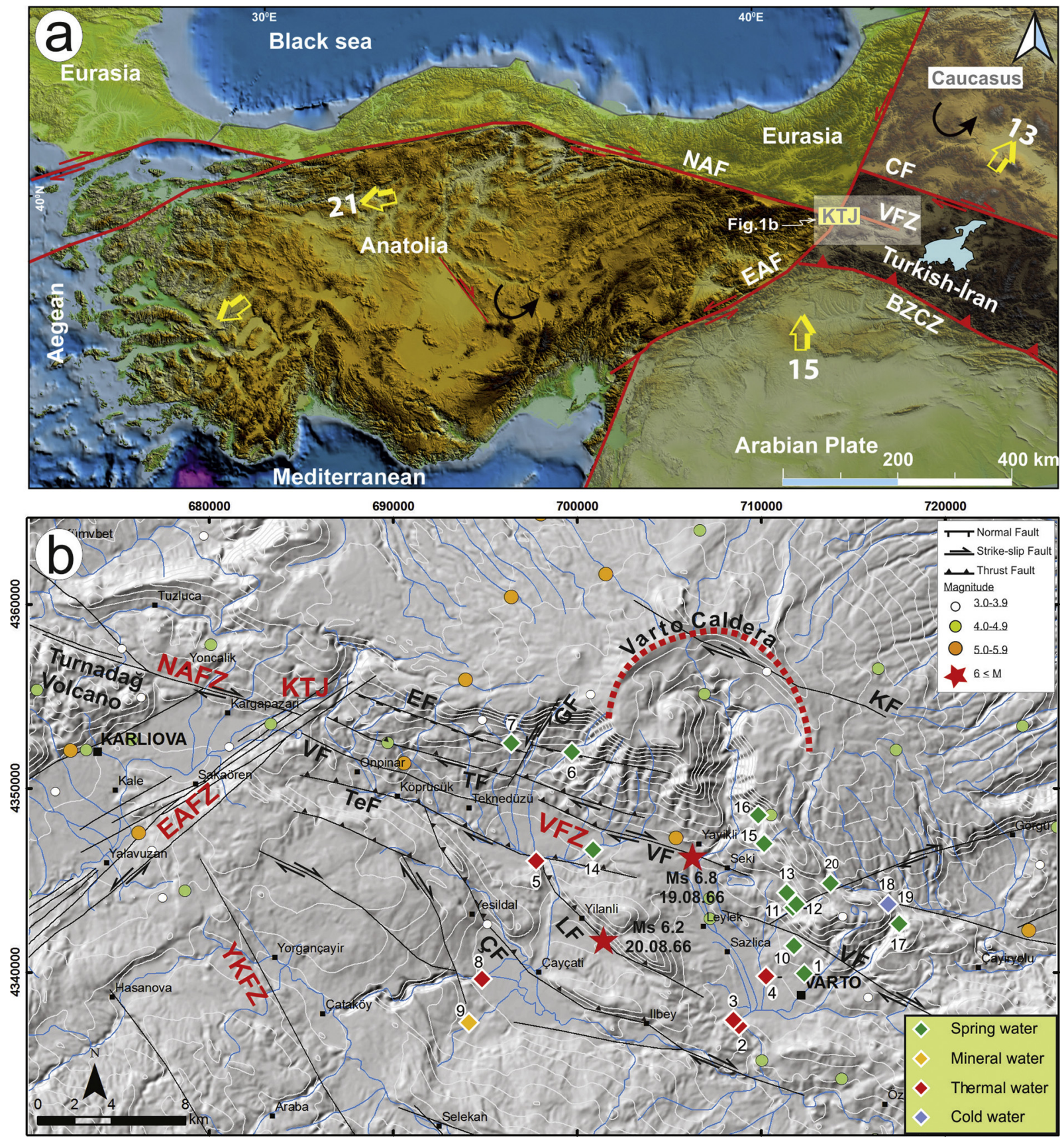

Fig. 1. a) Regional map showing crustal deformation in the eastern Mediterranean and Anatolia (Armijo et al., 1999). NAFZ: North Anatolian Fault Zone, EAFZ: East Anatolian Fault Zone, BZCZ: Bitlis-Zagros Collision Zone, CF: Çaldıran Fault, VFZ: Varto Fault Zone, YS: Yedisu Fault, KTJ: Karlıova Triple Junction; b) Shaded relief basis map showing locations of water sampling in the Varto region. The main faults and seismicity around the Karlova and Varto regions are modified from Herece (2008); Karaoğlu et al. (2017). Seismicity data is obtained from KOERI.

we present the kinematic data, which was previously published by Karaoğlu et al. (2017), on each fault segment around the Varto region (Fig. 3). The episodic deformation, which took place at Eryurdu, Tuzlu, Varto, Teknedüzü, Leylekdağ, and Çayçatı faults, dominate the southern part of the Varto Caldera (Fig. 3).

The Eryurdu Fault terminates the southern flank of the Varto Caldera resulting in fault-related volcanic breccia deposits. This fault is offset by the sinistral strike-slip Geyiksuyu Fault (GF) on the southern margin of the Varto Caldera (Fig. 3). The Eryurdu Fault strikes N85 ${ }^{\circ} \mathrm{W}$ and is around $18 \mathrm{~km}$ long with mostly high-angle and oblique-slip segments. This fault displays typical high-angle normal fault slickenlines (Fig. 3). Measurements indicate a well-preserved NNE-SSWtrending extension which formed from deformation of the southern part of the Varto caldera (Karaoğlu et al., 2017).

The Tuzla Fault is reported by Karaoğlu et al. (2017) as an active fault due to recorded seismic activities on this fault (Fig. 3). This fault is a thrust fault with a right-lateral component which extends laterally for over $20 \mathrm{~km}$ (Fig. 3). Fault kinematics suggest that it underwent a NW-SE directed compression with a maximum stress axis and that this compression has dominated for circa $6 \mathrm{Ma}$. The Pliocene deposits have been deformed by Tuzla Fault (Karaoğlu et al., 2017).

The N75 ${ }^{\circ} \mathrm{W}$-striking Varto Fault is composed of three sub-parallel segments which extend for $20 \mathrm{~km}$ (Fig. 3). A zone of distributed compression affects Pleistocene lacustrine sediments, which accommodate the deformation between the dextral faults. The easternmost segment of the Varto Fault shows dextral offsets for around $1.5 \mathrm{~km}$ in the valleys. 


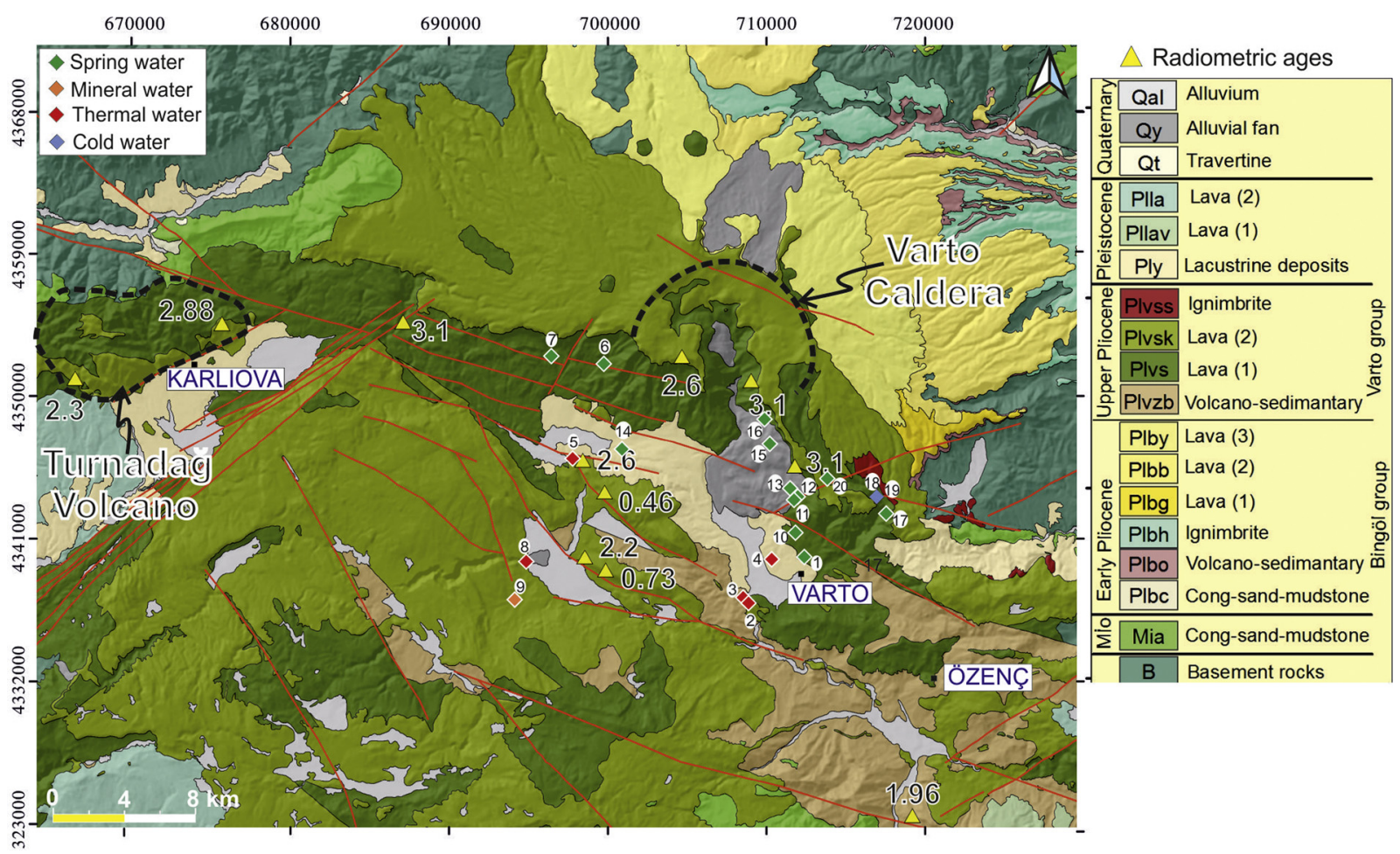

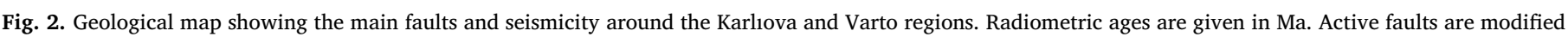

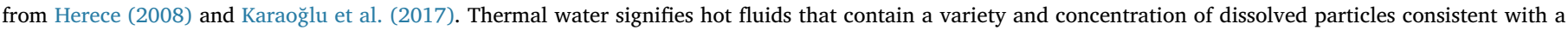

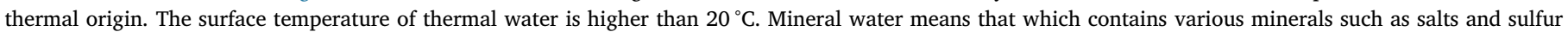
compounds. These waters have temperatures lower than $20^{\circ} \mathrm{C}$. Spring water is defined as natural water that was collected from underground sources.

Westernmost segments display some releasing step-over structures. Kinematic data for this fault poses oblique-slip normal fault surfaces dipping $55^{\circ} \mathrm{S}$ and with rakes of $35^{\circ} \mathrm{E}$ (Fig. 3).

The Teknedüzü Fault exhibits typical thrust fault constraints of $\mathrm{N} 75^{\circ} \mathrm{W}$-striking in different curved strands. The horsetail shape branches deformed up to $20 \mathrm{~km}$ in length of the fault (Fig. 3). This fault is regarded as one of the youngest faults because it cuts Pleistocene lava flows as well as recent lacustrine and alluvial deposits (Karaoğlu et al., 2017). The Teknedüzü Fault is represented by two main strands of The Leylekdağ and Çaydağ reverse faults, both have minor dextral strikeslip components (Fig. 3). The central part of the Leylekdağ Fault was ruptured by an earthquake (Mw 6.2) 20 August 1966.

The Varto region, where the thermal and non-thermal springs are most visible, has been subjected to intense deformation due to those reactivated faults. Fault planes of F9 and F10 record a NE-SW-directed contraction associated with a NW-SE extension, whilst a coeval phase of F11 developed under NE-SW extension (Fig. 3; Karaoğlu et al., 2017).

The Çayçatı Fault, which displays thrust fault kinematic morphological constraints, consists of two main segments. The western segment

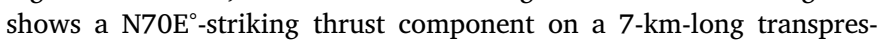
sional fault (Fig. 3). Evidence for the earthquake faulting scarps and related deformation generated by the 1966 earthquake can still be observed in this area. The kinematic data from F12 indicate that a NW-SE-trending extension is associated with the NE-SW contraction (Fig. 3; Karaoğlu et al., 2017).

Both extensional and transtensional dominated fault motions have been documented on the extruded Anatolian block (Karaoğlu et al., 2017) (Fig. 3). Measurements of stress tensors on the western part of the KTJ indicate E-W-trending extension which is compatible with the westward motion of the Anatolian block (Fig. 3). However, measurements from point F14 on Fig. 3 indicate a NE-SW-trending extension (Karaoğlu et al., 2017), point F13 on Fig. 3 indicates a sinistral strikeslip fault motion with at least two phases of movement. Both fault scarps suggest extensional tectonics along the East Anatolian Fault (Fig. 3) (Karaoğlu et al., 2017).

\section{Governing equations}

We present three sets of governing equations used to create models in COMSOL Multiphysics. They are mass balance, momentum and heat transfer.

The momentum and mass balance equations are as follows:

$-\nabla \cdot \eta\left(\nabla \mathbf{u}+(\nabla \mathbf{u})^{T}\right)+\frac{\eta}{k} \mathbf{u}+\nabla p=\mathbf{g} \beta_{T}\left(T-T_{c}\right)$

$\nabla \cdot \mathbf{u}=0$

where $\mathrm{p}$ is pressure, $\mathrm{u}$ is a vector of directional velocities, $\mathrm{h}$ is dynamic viscosity, $\mathrm{k}$ is permeability, $\mathrm{r}$ is fluid density, $\mathrm{g}$ is gravity, $\beta_{T}$ is thermal expansion coefficient, $\mathrm{T}$ is temperature from the heat transfer application, and $\mathrm{Tc}$ is the initial temperature.

A buoyant lifting term links flow and heat:

$\nabla \cdot\left(-k \nabla T+c_{p} \rho T \mathbf{u}\right)=0$

where, $\mathrm{T}$ is temperature, $\mathrm{K}_{\mathrm{e}}$ is effective thermal conductivity of the fluid and solid medium, $C_{L}$ is fluid volumetric heat capacity, $C_{L}=c_{p} r, c_{p}$ is fluid specific heat capacity, and $\mathrm{u}$ is a vector of directional fluid velocities from the flow application (Versteeg and Malalasekera, 1995).

The heat transport in this paper is described by the heat transport equation:

$\left(\rho C_{p}\right)_{e q} \partial T / \partial t+\rho C_{p} u . \nabla=\nabla \cdot\left(k_{e q} \nabla T\right)+Q+Q_{g e o}$

Heat is balanced generally and it is transported by both conduction and convection processes within a fault zone. Heat can be generated or lost, which can be defined in the source term, $Q$. One special feature of heat transfer at the porous medium interface is the hydrothermal heatingfeature implemented, represented as a domain condition: $Q_{g e o}$. It is also possible to implement an average representation of rock thermal 


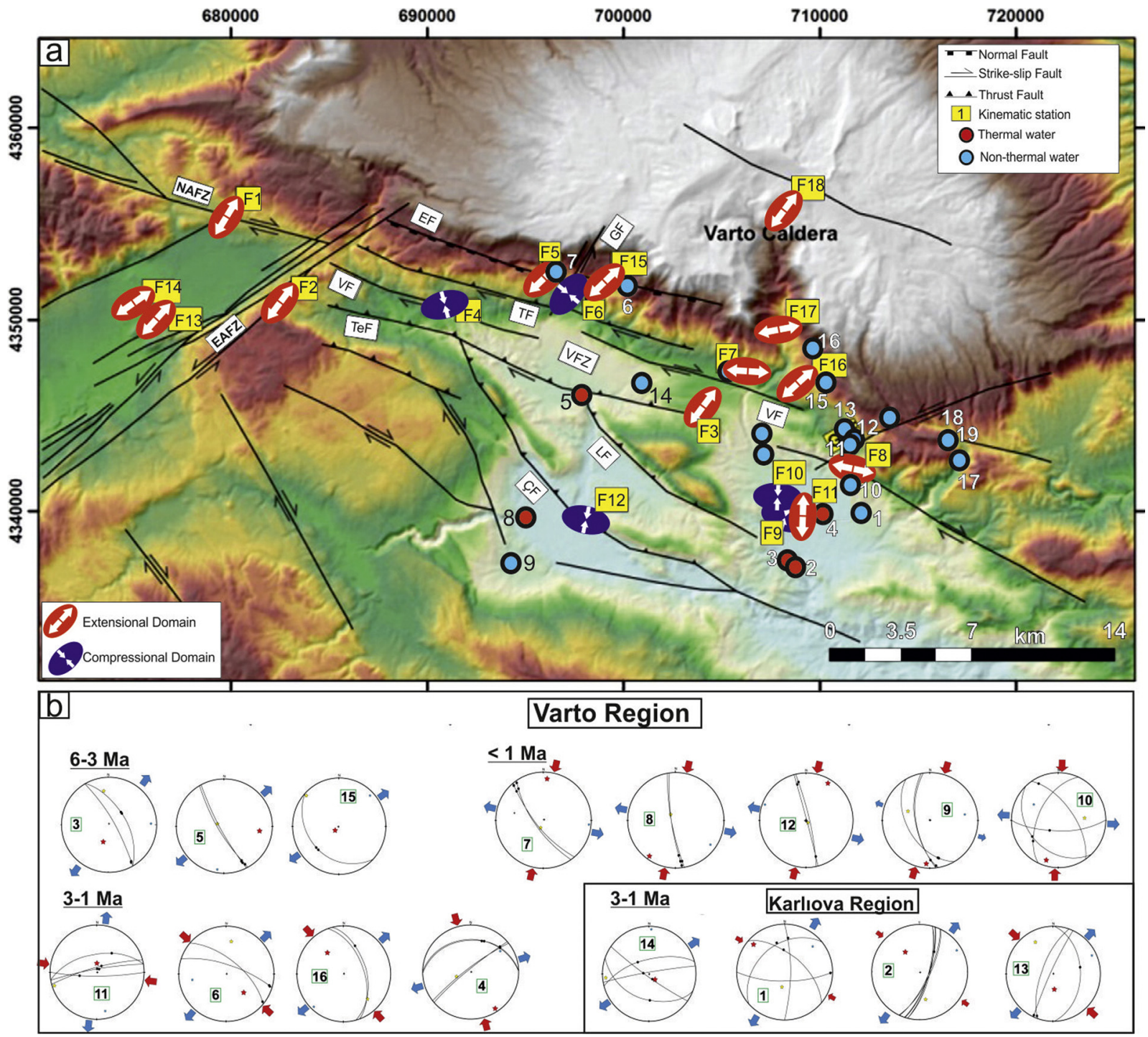

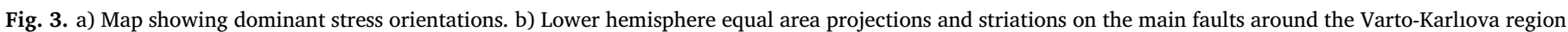
(data from Karaoğlu et al., 2017). Locations of the fluid measurement sites and kinematic stations are given in the map.

parameters, comprising the rock structure and the underground water using the matrix volume fraction, $\Theta$, as a weighting factor (for further details see the COMSOL website, www.comsol.com).

In the case of volume averaging, the volumetric heat capacity in the heat transport equation becomes:

$\left(\rho C_{p}\right)_{e q}=\sum_{i}\left(\theta_{p i} p_{p i} C_{p . p i}\right)+\left(1-\sum_{i} \theta_{p i}\right) \rho C_{p}$

and the thermal conductivity becomes:

$k_{e q}=\sum_{i}\left(\theta_{p i} k_{p i}\right)+\left(1-\sum_{i} \theta_{p i}\right) \rho C_{p}$

Solving the heat transport properly generally requires incorporation of a flow field. There are various situations in the subsurface which require different approaches to describe the fluid flow mathematically (Durbin, 1986). In this paper we focus on the macro-scale and also take into consideration resolution of flow in pores. However, fully-saturated and mainly pressure-driven flow in deep geothermal strata are sufficiently described by Darcy's law:

$u=-\frac{k}{\mu} \nabla p$

where the velocity field, $u$, depends on the permeability, $\kappa$, the fluid's dynamic viscosity, $\mu$ and is driven by a pressure gradient, P. Darcy's law is then combined with the continuity equation:

$\frac{\partial}{\partial t}\left(p \varepsilon_{p}\right)+\nabla \cdot(p u)=Q_{m}$

as our scenario concerns geothermal time scales, the time dependence is due to storage effects on the flow and heat transfer from the fluid to solid and vice versa. Therefore, the first term on the left-hand side of the equation above vanishes because the density, $\rho$, and the porosity, $\varepsilon_{p}$, can be assumed to be constant. Usually, the temperature dependencies of the hydraulic properties are also negligible. In some of our models, especially if the number of degrees of freedom is large, it can make sense to utilize independence by splitting the problem into a few time dependant and stationary sections for solution. In the following models, heat transfer from the fluid into solids is only due to conduction (Taler and Duda, 2006). Fourier's law also describes how to define the conductive heat flux, q. This shall be proportional to the temperature gradient:

$q=-k \nabla T$

$\left(\rho C_{p}\right)_{e q} \frac{\partial T}{\partial t}=\nabla \cdot\left(k_{e q} \nabla T\right)+Q$ 


\section{Methods}

\subsection{Field investigations}

To explore the thermo-mechanical relationships of the fault activity, hydrogeology, thermal and fluid circulation we carried out an extensive field study around the Varto-Karlova region (Fig. 1b). The sampling strategy was developed based on the geological map, cross sections, and also fault surfaces.

The sampling study was performed on five hot fluids and two mineral water springs, together with cold waters in November 2008 in the region shown in Fig. 1b. During the field surveys, some physical parameters of water, including $\mathrm{pH}$, electrical conductivity (EC as $\mu \mathrm{S} / \mathrm{cm}$ ), temperature $\left(\mathrm{T}\right.$ as $\left.{ }^{\circ} \mathrm{C}\right)$, redox potential (Eh as $\mathrm{mV}$ ) and flow rate ( $\mathrm{Q}$ as $\mathrm{L} /$ s), were measured in-situ with a WTW Multi 340i/SETS. For waterquality monitoring, four sets of samples were collected from each point: a $500 \mathrm{~mL}$ sample for major anions and cations; a $1000 \mathrm{~mL}$ sample for tritium isotopes; a $100 \mathrm{~mL}$ sample for oxygen-18 $\left({ }^{18} \mathrm{O}\right)$ and deuterium $\left({ }^{2} \mathrm{H}\right)$, and a $100 \mathrm{~mL}$ sample for heavy metals and trace elements. To prevent the complex formation of trace elements with oxygen, samples were filtered with $0.45 \mu \mathrm{m}$ filter paper, transferred to $50-\mathrm{mL}$ polyethylene bottles and stored at $4{ }^{\circ} \mathrm{C}$.

\subsection{Analytical methods}

The heavy metals and trace elements were acidified to $\mathrm{pH}<2$ conditions by adding $0.5 \mathrm{ml} \mathrm{HNO}_{3}$ to prevent the complex formation of trace elements with oxygen and then analyzed by inductively coupled plasma-mass spectroscopy (ICP-MS) at the ACME Laboratories in Canada. Chlorine and $\mathrm{HCO}_{3}{ }^{-}$were determined volumetrically and $\mathrm{SO}_{4}{ }^{2-}$ by a gravimetric method in the Hacettepe University in Ankara, Turkey.

The concentrations of $\delta{ }^{2} \mathrm{H}, \delta^{3} \mathrm{H}$ and $\delta^{18} \mathrm{O}$ isotopes in water samples were determined in the isotope laboratories of the Hacettepe University in Ankara, Turkey. The analysis was carried out in accordance with the standards defined by the International Atomic Energy Agency (Attendorn and Bowen, 1997). $\delta^{18} \mathrm{O}$ and $\delta^{2} \mathrm{H}$ analyses were conducted using an MS technique that had an uncertainty of $\pm 0.05 \%$ and \pm $1.0 \%$, respectively. These values are expressed conventionally in delta notation as a per-mil deviation from the V-SMOW (Vienna Standard Mean Ocean Water) (Verhagen et al., 1991). Tritium $\left(\delta^{3} \mathrm{H}\right)$ analysis was conducted with a liquid scintillation counter after electrolytic enrichment of the water samples with an error of \pm 0.8 tritium units (TU) (Attendorn and Bowen, 1997).

The data handling was performed by the descriptive manner of specifying water types (facies), their origins and average reservoir (host) rock temperature calculation. Piper and Schoeller diagrams are used to emphasize differences and similarities in terms of water types. Isotope signatures of samples indicate their origins. Solute geothermometer equations were applied to calculate average reservoir rock temperatures.

\subsection{Hydrogeochemical properties of water resources}

The preliminary evaluation of geological conditions at the site provides some information regarding depths of water circulation, bearing potential of the rocks and their influence on spring water chemistry. To represent the chemistry of the site, twenty water points were sampled, including five hot water springs, two mineral water springs, and twelve spring water and surface water (cold water) (Fig. 1b).

The average discharge of thermal springs ranges from 1 to $5 \mathrm{~L} / \mathrm{sec}$ in the study area (Fig. 1b) (Table 1). Surface temperatures of these springs range from $22.5-32{ }^{\circ} \mathrm{C}$, with electrical conductivity (EC) values from 2100 to $5775 \mu \mathrm{S} / \mathrm{cm}$. The average discharges of mineral waters at that site are between 0.5 and $2 \mathrm{~L} / \mathrm{sec}$. Surface temperatures were measured as 13.2 and $14.8^{\circ} \mathrm{C}$. Their electrical conductivity values are also in the range of $719-751 \mu \mathrm{S} / \mathrm{cm}$. The average discharges of cold water springs in the study area are between 1 and $150 \mathrm{~L} / \mathrm{sec}$. Surface temperatures of these springs vary between 4.9 and $11.7^{\circ} \mathrm{C}$ and electrical conductivity values range from 51 to $199 \mu \mathrm{S} / \mathrm{cm}$. Regarding $\mathrm{pH}$ values, water samples belonging to the site are entirely in the $\mathrm{pH}$ range of $\sim 5.4-\sim 6.2$ for hot and mineral waters, and $\sim 6.2$ to 7.7 for cold waters. Thermal springs have acid character, whereas $\mathrm{pH}$ values for cold water springs change from slightly acid, neutral to slightly basic. The ranges of physical parameters measured are affected by outcropping rocks and structural features of the site allow different circulation depths.

Volcanic and sedimentary rocks outcrop in the vicinity of the study area and the groundwater flow in the volcanic rocks appears to be controlled by the presence of structural features. The information indicating the circulation depth only arises from alignments of the springs. Thermal, mineral and cold water springs discharge from rocks of Upper Miocene and Upper Pliocene age (Yolüstü Formation of Upper Pliocene, Kohkale Lava and Zirnak Formation of Upper Miocene in Fig. 2).

These rocks include both volcanic rocks and intercalated volcanic rocks with continental deposits such as sandstone; therefore, they are water-bearing formations. In addition to this, the NAF in Upper Miocene rocks which can outcrop in the study area controls groundwater transport (see Fig. 1b). Shallow and deep flow paths for the groundwater are reflected in the chemistry of the springs (Table 2). The deep flow paths of groundwater resources consist of more ions than the shallow flow groundwater paths.

On the basis of major ion chemistry, the Piper and Schoeller diagrams for the study area are shown in Fig. 4. Both diagrams give not only information about different water types at the site but also their evolution. According to the Schoeller diagram, cold waters can be distinguished easily with low major cations and chloride when compared with geothermal and mineral waters. According to the Piper diagram and water type classification (Deutsch and Siegel, 1997), thermal springs are of $\mathrm{Na}-\mathrm{HCO}_{3}-\mathrm{Cl}$ and $\mathrm{Mg}-\mathrm{Na}-\mathrm{HCO}_{3}$ types; while mineral and cold waters are of $\mathrm{Ca}-\mathrm{HCO}_{3}$ type. To compare the thermal waters with mineral and cold waters, a Cl-SO $-\mathrm{HCO}_{3}$ a ternary plot was used (Fig. 5). This diagram covers the entire spectrum of naturally occurring waters from virtually pure chloride, over mixed chloridesulfate, to bicarbonate (Giggenbach, 1988; Nicholson, 1993). For the hydrogeochemical data, relative portions of $\mathrm{Cl}-\mathrm{SO}_{4}-\mathrm{HCO}_{3}$ cluster into steam-condensates and dilute $\mathrm{Cl}-\mathrm{HCO}_{3}$ sectors (Fig. 5); see the data labeled 2. According to the scatter diagram each thermal fluid has different concentration of $\mathrm{SO}_{4}{ }^{2-}$ ions (Fig. 6). Sample 2 has a high $\mathrm{SO}_{4}{ }^{2-}$ concentration which comes from volcanic units.

The hydrogeochemical facies map of the area is shown in Fig. 7. As seen in Fig. 7, the lower altitudes contain geothermal waters and the zone of $\mathrm{Na}-\mathrm{HCO}_{3}-\mathrm{Cl}$. Cold waters discharge at higher altitudes and they represent the zone of $\mathrm{Ca}-\mathrm{HCO}_{3}$.

When taking account of the linear arrangement of plotted data in Fig. 4 and the processes of steam condensates and dilution with chloride acting upon them, water types change from dominant $\mathrm{Ca}^{2+}$ and $\mathrm{HCO}_{3}{ }^{-}$ions to dominant $\mathrm{Na}^{+}$and $\mathrm{Cl}^{-}$ions as expressed in Eq. (11).

$\mathrm{Ca}-\mathrm{HCO}_{3} \rightarrow \mathrm{Ca}-\mathrm{Na}-\mathrm{HCO}_{3} \rightarrow \mathrm{Na}-\mathrm{HCO}_{3}-\mathrm{Cl}$

$\mathrm{Na}^{+}$and $\mathrm{Cl}^{-}$ions are obtained from the altered volcanic rocks. Consequently, volcanic rocks at the site appear to be the likely host rock owing to enrichment of $\mathrm{Na}^{+}$and $\mathrm{Cl}^{-}$ions in the water and abundance of those elements in minerals in the volcanic rocks. In addition, it is clear that thermal waters have relatively deeper circulation routes than cold water under the assumption that they are fluids ascending due to deep processes (water-rock interaction, boiling, and steam heating; see Nicholson, 1993 for details) which do not affect their isotope compositions and originate in descending cold waters. 
Table 1

Physical properties of water resources around the study area.

\begin{tabular}{|c|c|c|c|c|c|c|c|c|c|c|}
\hline No & Easting & Northing & Elevation (m) & Location & $\mathrm{T}\left({ }^{\mathrm{O}} \mathrm{C}\right)$ & $\mathrm{Q}(1 / \mathrm{s})$ & $\mathrm{Ec}(\mu \mathrm{S} / \mathrm{cm})$ & $\mathrm{pH}$ & Salinity (\%) & Type \\
\hline 1 & 712506 & 4339901 & 1573 & Tas Cesme & 11.6 & 3 & 187 & 6.22 & 0 & Spring \\
\hline 2 & 708927 & 4337029 & 1465 & Alagoztepe Kaplicasi & 29.0 & $3-5$ & 5775 & 6.04 & 3.3 & Hot water \\
\hline 3 & 708625 & 4337352 & 1434 & Alagoztepe Dere Kaplicasi & 26.8 & 5 & 2100 & 6.09 & 1 & Hot water \\
\hline 4 & 710407 & 4339752 & 1497 & Dipsiz Gol Kaynagi & 22.5 & $1-2$ & 2845 & 6.19 & 1.4 & Hot water \\
\hline 5 & 697835 & 4346054 & 1520 & Guzelkent Koyu & 28.2 & 1 & 2155 & 5.75 & 1 & Hot water \\
\hline 6 & 699782 & 4352013 & 2072 & TasliYayla & 8.9 & 2 & 77 & 7.72 & 0 & Spring \\
\hline 7 & 696479 & 4352499 & 2050 & Hizir Cesme & 8.6 & 50 & 61 & 7.09 & 0 & Spring \\
\hline 8 & 694874 & 4339601 & 1472 & Baskan Kaplicasi & 32.0 & & 2334 & 6.06 & 1.1 & Hot water \\
\hline 9 & 694153 & 4337217 & 1524 & Baskan Koyu Maden suyu & 14.8 & 2 & 751 & 6.16 & 0.1 & Mineral Water \\
\hline 10 & 711941 & 4341403 & 1659 & Acarkent Koyu Kaynagi & 11.0 & $1-2$ & 136 & 6.50 & 0 & Spring \\
\hline 11 & 711876 & 4343505 & 1848 & Oglakci Koyu iki goze 1 & 10.3 & 2.5 & 115 & 6.54 & 0 & Spring \\
\hline 12 & 712072 & 4343678 & 1910 & Soguk Gol Kaynagi & 7.2 & & 60 & 6.68 & 0 & Spring \\
\hline 13 & 711587 & 4344202 & 1857 & Yali Golu- Oglakci Koyu & 9.2 & 1 & 105 & 6.73 & 0 & Spring \\
\hline 14 & 700947 & 4346658 & 1936 & Seki Koyu Kaynagi & 9.2 & 1.8 & 90 & 6.93 & 0 & Spring \\
\hline 15 & 710297 & 4346997 & 2089 & Cadir Baba Kaynagi & 6.7 & 1 & 63 & 7.09 & 0 & Spring \\
\hline 16 & 709989 & 4348552 & 2147 & Seki Koyu Seker Kaynagi & 4.9 & & 51 & 7.34 & 0 & Spring \\
\hline 17 & 717689 & 4342614 & 1940 & Deregolluk Kaynaklari & 7.5 & 1.5 & 87 & 7.11 & 0 & Spring \\
\hline 18 & 717105 & 4343680 & 1901 & Kamerkomu Maden suyu & 13.2 & 0.5 & 719 & 5.41 & 0.1 & Mineral Water \\
\hline 19 & 717105 & 4343680 & 1901 & Hotan Deresi & 6.0 & 150 & 63 & 7.30 & 0 & Surface Water \\
\hline 20 & 713930 & 4344827 & 2120 & Hotan Kaynagi & 5.4 & 1.5 & 52 & 6.42 & 0 & Spring \\
\hline
\end{tabular}

\subsubsection{Isotope composition of water samples}

$\delta^{18} \mathrm{O}(\%)$ and $\delta^{2} \mathrm{H}(\%)$ composition of the selected samples is essential to explore whether or not they are meteoric or processed waters. Craig (1961) demonstrated that the $\delta 180(\%)$ and $\delta 2 \mathrm{H}(\% 0)$ ratios of meteoric waters (precipitation, river and lake samples from various countries) fit to a line known as the global meteoric water line (GMWL) represented by the formula in Eq. (12).

$\delta \mathrm{D}=8 \delta^{18} \mathrm{O}+10$

However, $\delta^{18} \mathrm{O}$ and $\delta \mathrm{D}$ values at any locality are strongly dependent upon distance from the ocean (continental effect), latitude and altitude (Nicholson, 1993). Thereby, regional (RMWL) and especially local meteoric water lines (LMWL) are convenient references for understanding local groundwater isotope variations with reference to local meteoric waters (Mazor, 2004). Isotope signatures of groundwater can shift from meteoric water lines to schematic trends designating processes; each process represents a shift in isotopic composition to the extent that $\delta^{2} \mathrm{H}$ as well as $\delta^{18} \mathrm{O}$ enriched. Isotope processes can be separated as surficial and deep processes including surface evaporation for the former; and water-rock interaction, steam heating and boiling for the latter respectively. Groundwater influenced by these processes is defined as processed water mentioned in the first line of this section. To explore whether the selected samples are processed or not, selected RMWLs (Gat, 1983; Eisenlohr, 1995) and LMWLs (Sayın and Eyüpoğlu, 2005) are used (Eq. (13)) and the site data given in Table 3 are plotted (Fig. 8).

$\delta \mathrm{D}=8 \delta^{18} \mathrm{O}+22.00$ (Eastern Mediterranean)

$\delta \mathrm{D}=8 \delta^{18} \mathrm{O}+16.00$ (Marmara)

$\delta \mathrm{D}=8 \delta^{18} \mathrm{O}+10.00$ (Global \& Central Anatolia)

$\delta \mathrm{D}=8 \delta^{18} \mathrm{O}+11.36$ (Dalbahçe-Erzurum)

$\delta \mathrm{D}=8 \delta^{18} \mathrm{O}+14.87$ (Şenyurt-Erzurum)

The data are separated as thermal and cold waters in the diagram and clustered between the RMWL of Eastern Mediterranean and Marmara. Isotope signatures of the site data do not show any trend indicating processes.

The activity of $\delta^{3} \mathrm{H}$ indicates groundwater circulation time consumed from recharge to discharge and can be simply stated that as the

Table 2

Major anion and cations in water resources around the study area.

\begin{tabular}{|c|c|c|c|c|c|c|c|c|c|c|c|c|c|c|}
\hline NO & $\begin{array}{l}\mathrm{Na}^{+} \\
\mathrm{mg} / \mathrm{L}\end{array}$ & $\begin{array}{l}\mathrm{K}^{+} \\
\mathrm{mg} / \mathrm{L}\end{array}$ & $\begin{array}{l}\mathrm{Mg}^{2+} \\
\mathrm{mg} / \mathrm{L}\end{array}$ & $\begin{array}{l}\mathrm{Ca}^{2+} \\
\mathrm{mg} / \mathrm{L}\end{array}$ & $\begin{array}{l}\mathrm{Cl}^{-} \\
\mathrm{mg} / \mathrm{L}\end{array}$ & $\begin{array}{l}\mathrm{NO}_{2}{ }^{-} \\
\mathrm{mg} / \mathrm{L}\end{array}$ & $\begin{array}{l}\mathrm{NO}_{3}{ }^{-} \\
\mathrm{mg} / \mathrm{L}\end{array}$ & $\begin{array}{l}\mathrm{PO}_{4}{ }^{3-} \\
\mathrm{mg} / \mathrm{L}\end{array}$ & $\begin{array}{l}\mathrm{SO}_{4}= \\
\mathrm{mg} / \mathrm{L}\end{array}$ & $\begin{array}{l}\mathrm{CO}_{3}{ }^{-} \\
\mathrm{mg} / \mathrm{L}\end{array}$ & $\begin{array}{l}\mathrm{HCO}_{3}{ }^{-} \\
\mathrm{mg} / \mathrm{L}\end{array}$ & $\begin{array}{l}\mathrm{Li}^{+} \\
\mathrm{mg} / \mathrm{L}\end{array}$ & $\begin{array}{l}\mathrm{F}^{-} \\
\mathrm{mg} / \mathrm{L}\end{array}$ & $\begin{array}{l}\mathrm{Br}^{-} \\
\mathrm{mg} / \mathrm{L}\end{array}$ \\
\hline 1 & 6.34 & 2.44 & 7.82 & 25.03 & 2.55 & 0.00 & 6.56 & 0.00 & 4.40 & 0.00 & 110.91 & 0.00 & 0.05 & 0.00 \\
\hline 2 & 970.00 & 77.15 & 177.38 & 218.69 & 1076.99 & 0.00 & 4.22 & 0.00 & 38.70 & 0.00 & 1971.72 & 1.26 & 0.13 & 0.91 \\
\hline 3 & 335.25 & 30.35 & 83.48 & 100.42 & 208.93 & 0.16 & 0.49 & 0.00 & 15.26 & 0.00 & 1139.04 & 0.50 & 0.38 & 0.12 \\
\hline 4 & 269.07 & 25.78 & 182.74 & 189.52 & 77.31 & 0.00 & 0.51 & 0.00 & 0.86 & 0.00 & 2069.68 & 0.75 & 0.17 & 0.07 \\
\hline 5 & 269.04 & 30.99 & 118.06 & 115.20 & 102.94 & 0.00 & 0.39 & 0.00 & 11.89 & 0.00 & 1391.91 & 0.60 & 0.21 & 0.16 \\
\hline 6 & 3.85 & 0.84 & 2.67 & 26.49 & 0.55 & 0.01 & 6.02 & 0.00 & 1.56 & 0.00 & 89.34 & 0.00 & 0.06 & 0.00 \\
\hline 7 & 2.64 & 1.14 & 2.10 & 7.08 & 0.27 & 0.00 & 2.06 & 0.03 & 0.86 & 0.00 & 33.89 & 0.00 & 0.04 & 0.00 \\
\hline 8 & 225.05 & 34.00 & 131.36 & 200.65 & 37.44 & 0.00 & 0.00 & 0.00 & 20.09 & 0.00 & 1688.28 & 0.40 & 0.15 & 0.00 \\
\hline 9 & 22.13 & 6.07 & 50.52 & 90.75 & 3.53 & 0.09 & 0.29 & 0.00 & 9.54 & 0.00 & 532.98 & 0.02 & 0.19 & 0.00 \\
\hline 10 & 5.66 & 1.89 & 5.57 & 15.72 & 0.75 & 0.00 & 4.82 & 0.12 & 1.50 & 0.00 & 77.02 & 0.00 & 0.09 & 0.00 \\
\hline 11 & 4.12 & 2.30 & 4.47 & 14.87 & 1.06 & 0.00 & 5.20 & 0.14 & 2.00 & 0.00 & 73.94 & 0.00 & 0.04 & 0.00 \\
\hline 12 & 2.68 & 1.23 & 2.47 & 13.22 & 0.28 & 0.00 & 1.99 & 0.00 & 0.83 & 0.00 & 58.60 & 0.00 & 0.04 & 0.00 \\
\hline 13 & 4.08 & 1.29 & 4.38 & 13.28 & 0.53 & 0.00 & 5.33 & 0.04 & 1.49 & 0.00 & 70.92 & 0.00 & 0.04 & 0.01 \\
\hline 14 & 3.68 & 1.36 & 3.58 & 16.07 & 0.63 & 0.00 & 5.83 & 0.02 & 1.67 & 0.00 & 67.78 & 0.00 & 0.03 & 0.00 \\
\hline 15 & 2.63 & 1.55 & 2.41 & 8.45 & 0.51 & 0.00 & 3.19 & 0.02 & 2.03 & 0.00 & 36.91 & 0.00 & 0.02 & 0.00 \\
\hline 16 & 2.35 & 1.06 & 2.08 & 7.06 & 0.23 & 0.00 & 3.14 & 0.00 & 0.78 & 0.00 & 33.83 & 0.00 & 0.01 & 0.00 \\
\hline 17 & 4.78 & 0.97 & 2.60 & 12.69 & 0.44 & 0.00 & 2.13 & 0.00 & 1.55 & 0.00 & 58.54 & 0.00 & 0.05 & 0.00 \\
\hline 18 & 52.80 & 18.58 & 27.47 & 84.29 & 4.05 & 0.00 & 0.00 & 0.00 & 6.44 & 0.00 & 499.09 & 0.06 & 0.21 & 0.00 \\
\hline 19 & 3.24 & 1.38 & 2.08 & 7.53 & 0.29 & 0.04 & 1.33 & 0.00 & 0.85 & 0.00 & 36.91 & 0.00 & 0.05 & 0.00 \\
\hline 20 & 2.59 & 1.34 & 1.61 & 8.08 & 0.29 & 0.00 & 3.01 & 0.00 & 0.99 & 0.00 & 33.89 & 0.00 & 0.04 & 0.00 \\
\hline
\end{tabular}




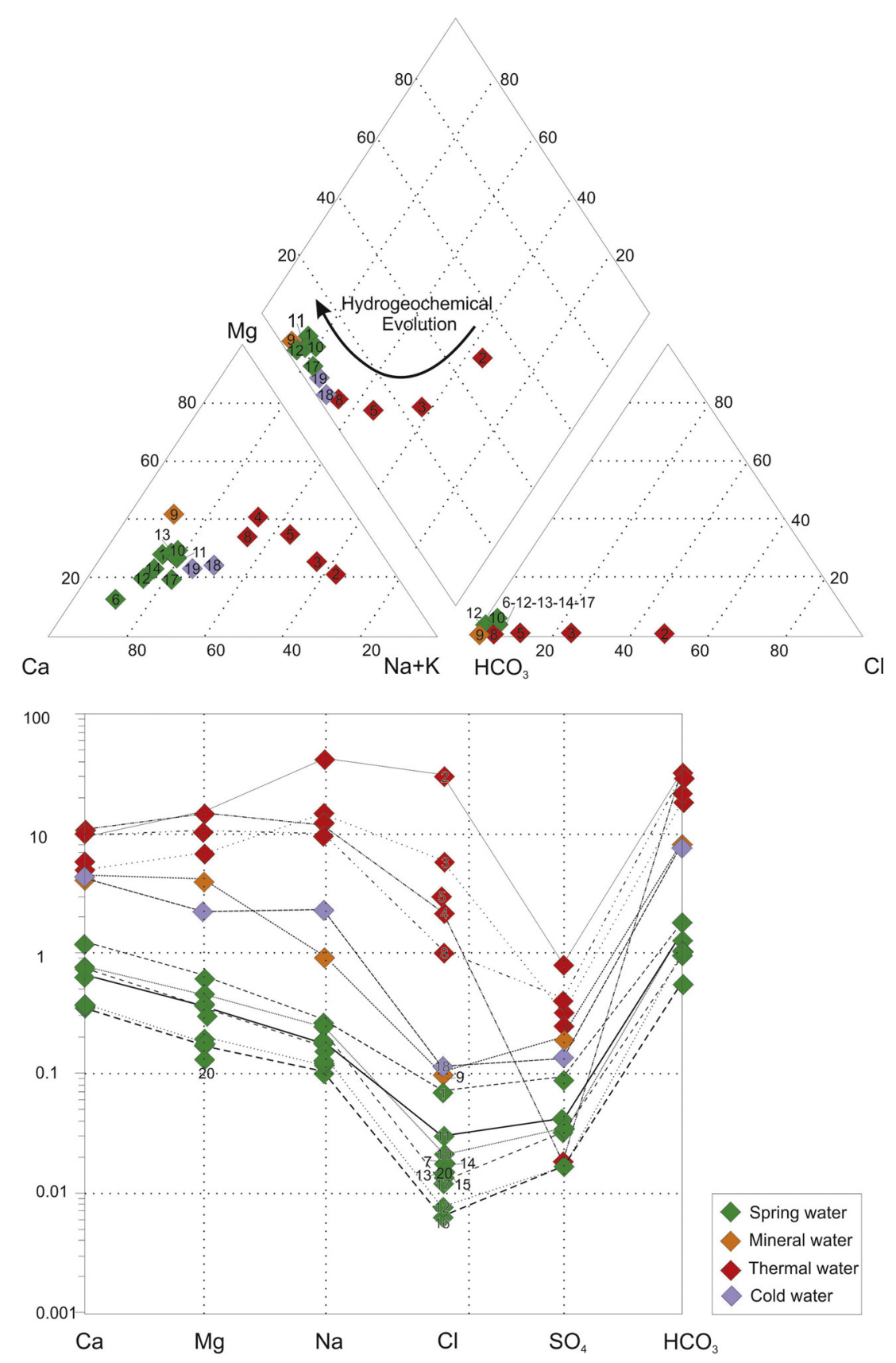

Fig. 4. a) Piper and b) Schoeller diagrams for the water resources in the study area. The red dots: thermal water, green dots: spring water, yellow dots: mineral water and blue dots: cold water (For interpretation of the references to colour in this figure legend, the reader is referred to the web version of this article.).

lower the $\delta^{3} \mathrm{H}$ activity in groundwater, the older it is or it has taken a longer route. This statement is applicable under the assumption of the piston flow model (no dispersion or mixing between different aged flow paths; see Kazemi et al., 2006 for details). In this model, the passage of time through which the activity of ${ }^{3} \mathrm{H}$ decreases can be calculated by the decay law in Eq. (14) (Kresic, 2007).

${ }^{3} \mathrm{H}_{\mathrm{s}}={ }^{3} \mathrm{H}_{\mathrm{o}} \mathrm{e}^{-\lambda \mathrm{t}}$

where ${ }^{3} \mathrm{H}_{\mathrm{s}}$ is the amount of ${ }^{3} \mathrm{H}$ in the sample, ${ }^{3} \mathrm{H}_{\mathrm{o}}$ is the activity of ${ }^{3} \mathrm{H}$ in precipitation, and $\lambda$ is the decay constant of tritium of 0.056 year $^{-1}$. In this equation, the most important point is to determine the $\delta^{3} \mathrm{H}$ activity in precipitation, essentially needed for the use of $\delta^{3} \mathrm{H}$ as a tracer of groundwater circulation time. Therefore, the activity of $\delta^{3} \mathrm{H}$ atoms in precipitation water should be measured to determine peak values of natural $\delta^{3} \mathrm{H}$ activity. These types of measurements are related to thermonuclear testing begun in 1952 (Kazemi et al., 2006). During the tests, large quantities of tritium were released into the atmosphere; hence, natural $\delta^{3} \mathrm{H}$ in precipitation between 5 and 20 tritium units (TU) stated by Kaufmann and Libby (1954) reached up to several thousand TU in precipitation (Mazor, 2004). To sum up, in the year 1952 the start of thermonuclear tests provided an indicator to determine pre and post1952 recharge entering into aquifers. To estimate pre and post-1952 recharge at the site, $\delta^{3} \mathrm{H}$ values in Table 3 are used.

The results indicate that $\delta^{3} \mathrm{H}$ values lower than $6 \mathrm{TU}$ indicate mixing of pre and post-1952 recharges, whereasvalues higher than $6 \mathrm{TU}$ are a sign of post-1952 recharge. Except for the spring labeled 1 which indicates cold water (post-1952), all thermal waters are mixed with cold waters. In conclusion, although thermal water samples cluster in steamheated/condensates and dilute $\mathrm{Cl}-\mathrm{HCO}_{3}$ sectors on the $\mathrm{Cl}-\mathrm{SO}_{4}-\mathrm{HCO}_{3}$ ternary plot (Fig. 9) they do not shift from meteoric water lines. 


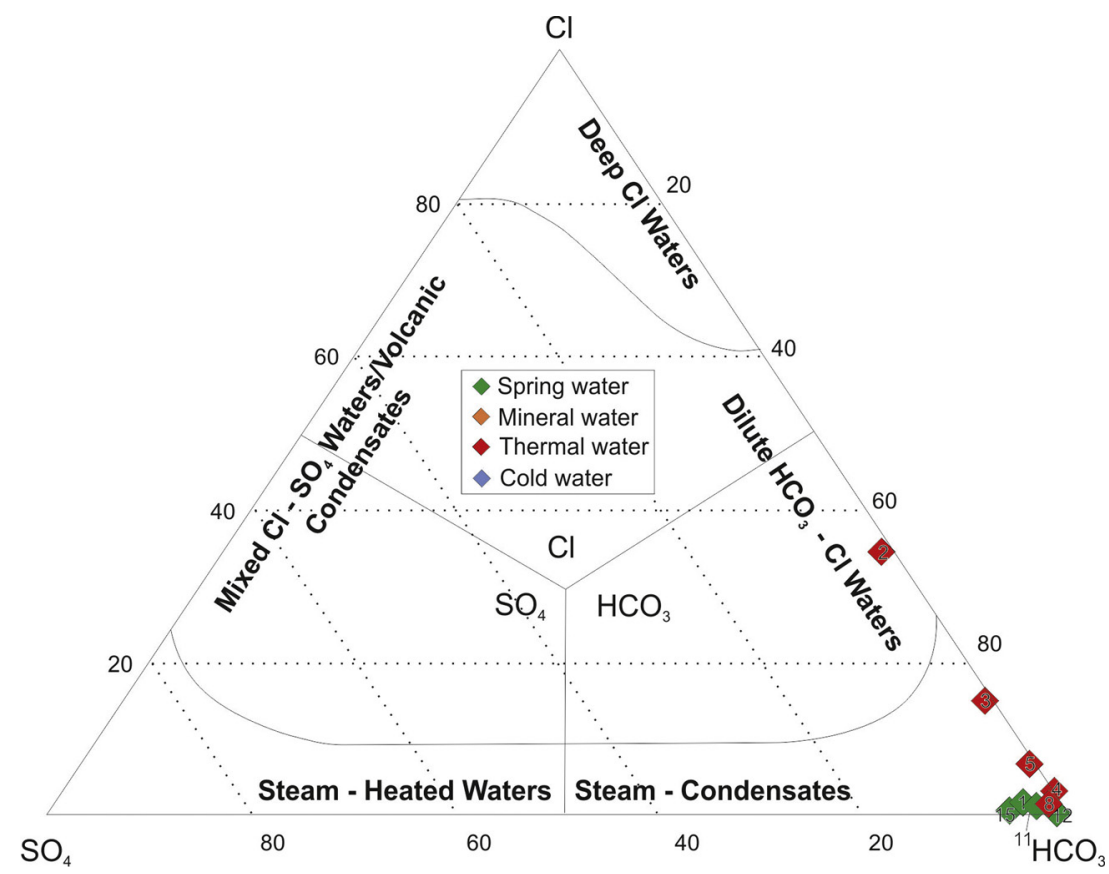

Fig. 5. $\mathrm{Cl}_{-} \mathrm{SO}_{4}-\mathrm{HCO}_{3}$ Ternary diagram for the water resources in the study area.

Therefore, steam-heated conditions are available for the site but for robust checking, solute geothermometers were used. It was expected that the host rock temperature is lower than that at steam condensate conditions.

\subsubsection{Application of geothermometers to the site data}

Chemical analyses of geothermal fluids can be used to estimate subsurface reservoir temperature. The results are given in Table 4. For robust checking, appropriate solution geothermometers given are explained by providing Giggenbach (1988) and SI diagrams (Reed and Spycher, 1984). The ternary plot of $\mathrm{Na} / 1000-\mathrm{K} / 100-\mathrm{Mg}^{1 / 2}$ of

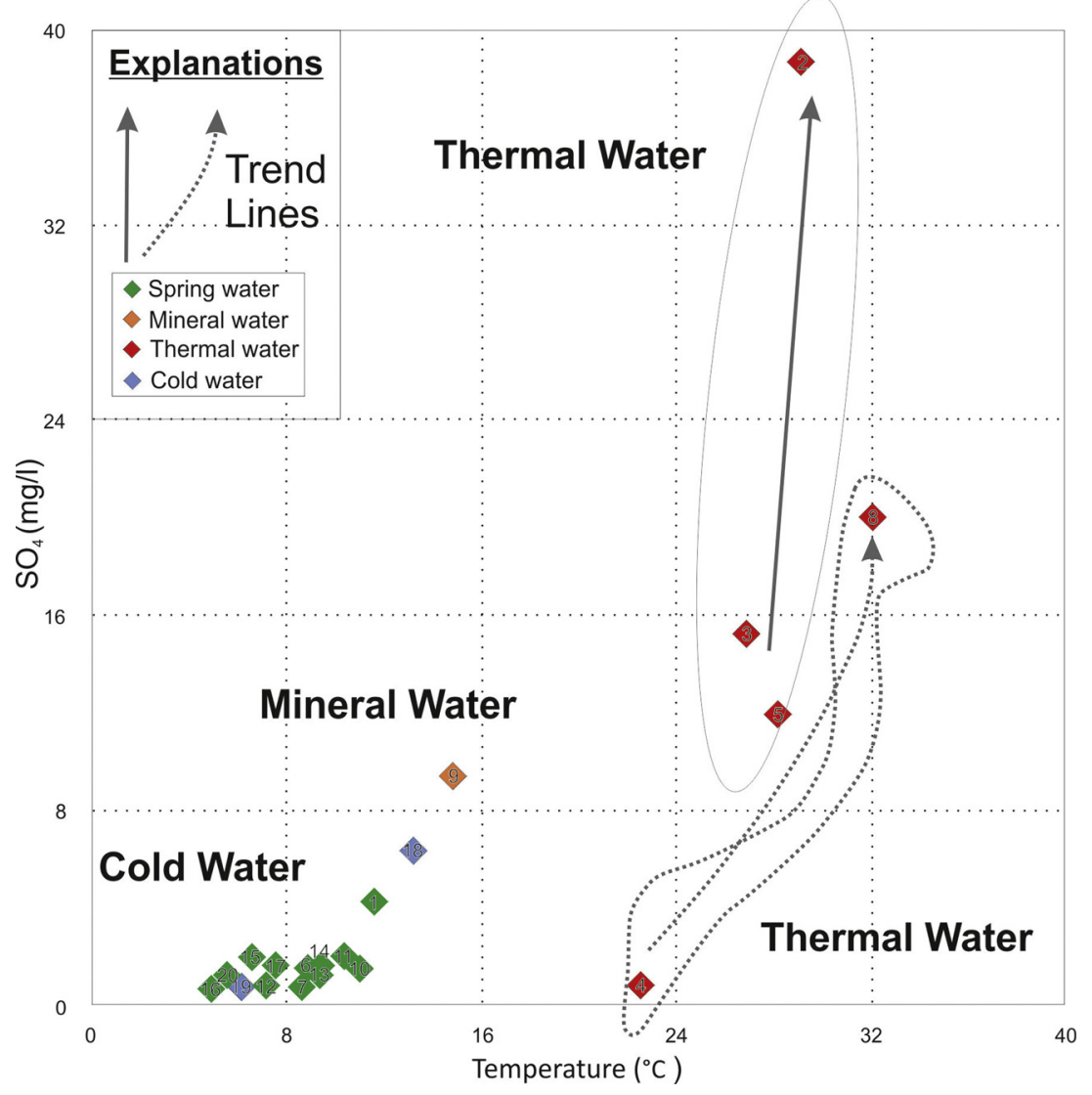

Fig. 6. Scatter diagram and trend lines for the water resources in the study area. 


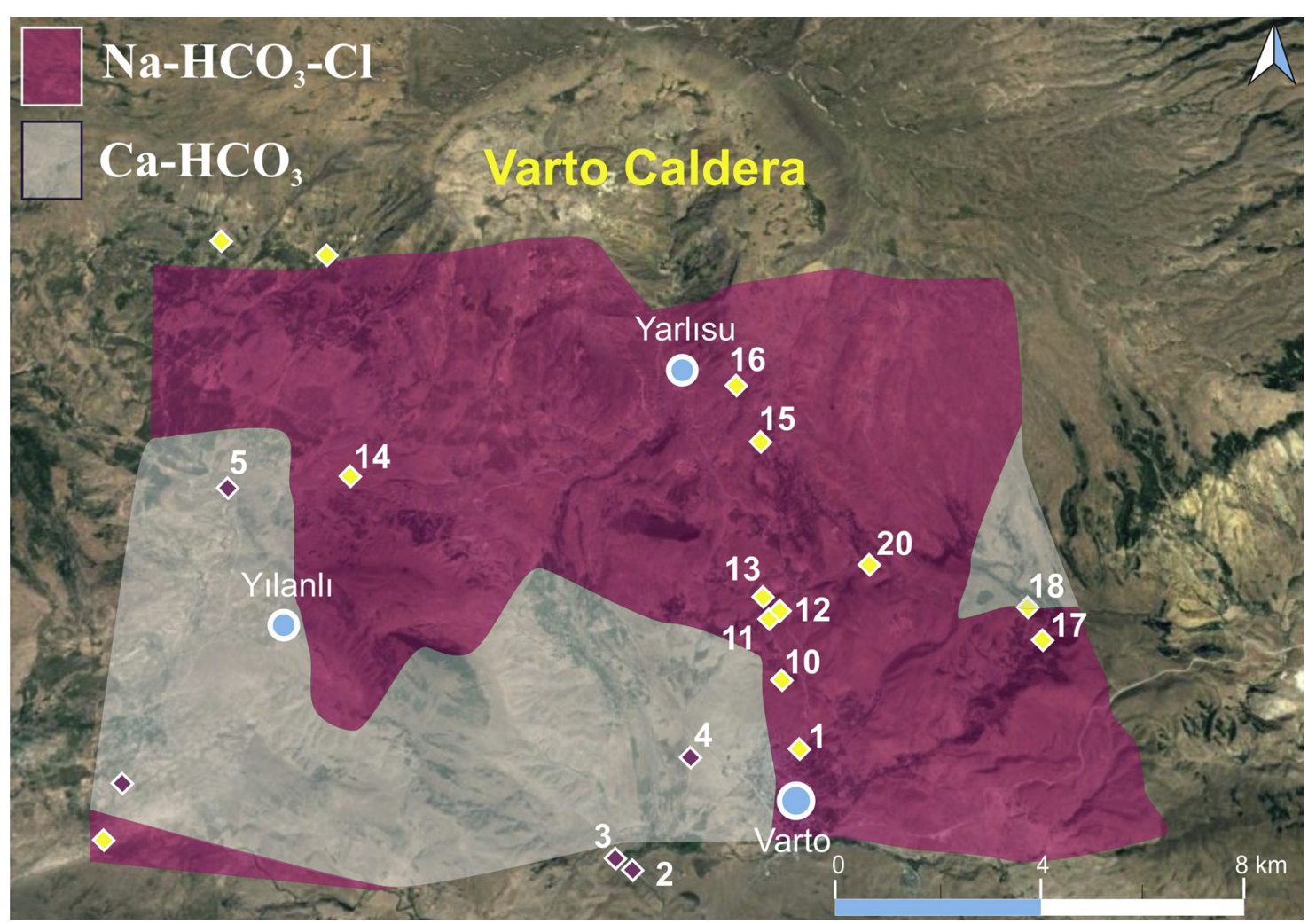

Fig. 7. Hydrogeochemical facies map of the site.

Table 3

Isotope values of the selected samples.

\begin{tabular}{llll}
\hline Sample No & $\delta^{18} \mathrm{O}(\%)$ & $\delta^{2} \mathrm{H}(\%)$ & $\delta^{3} \mathrm{H}$ Values (TU) \\
\hline 1 & -10.59 & -65.86 & 6.40 \\
3 & -12.51 & -82.50 & 0.40 \\
4 & -12.48 & -78.47 & 0.00 \\
5 & -12.17 & -79.81 & 0.95 \\
8 & -12.50 & -80.41 & 0.20 \\
\hline
\end{tabular}

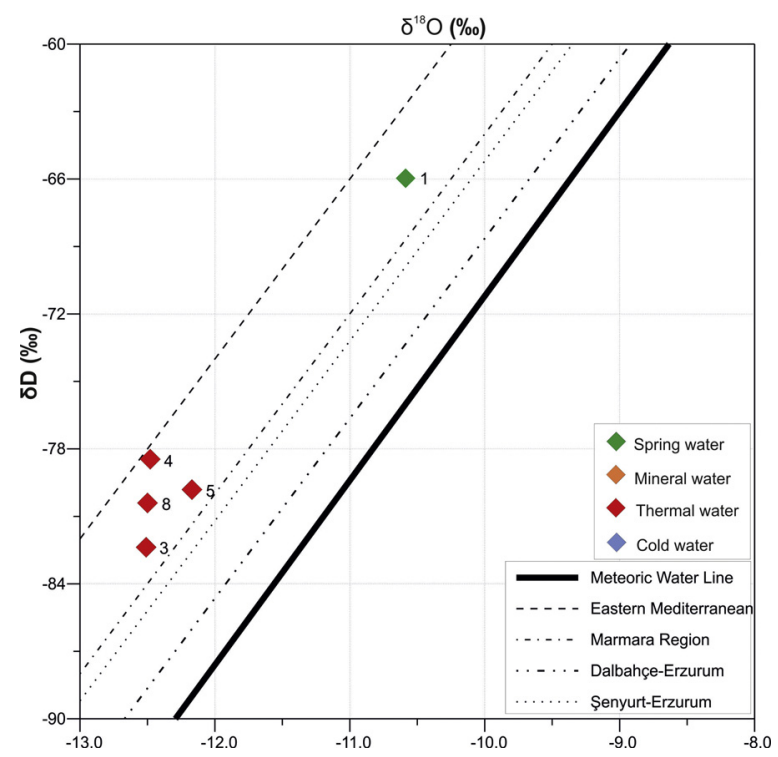

Fig. 8. $\delta^{18} \mathrm{O}$ versus $\delta \mathrm{D}$ diagram for the thermal waters in the study area.

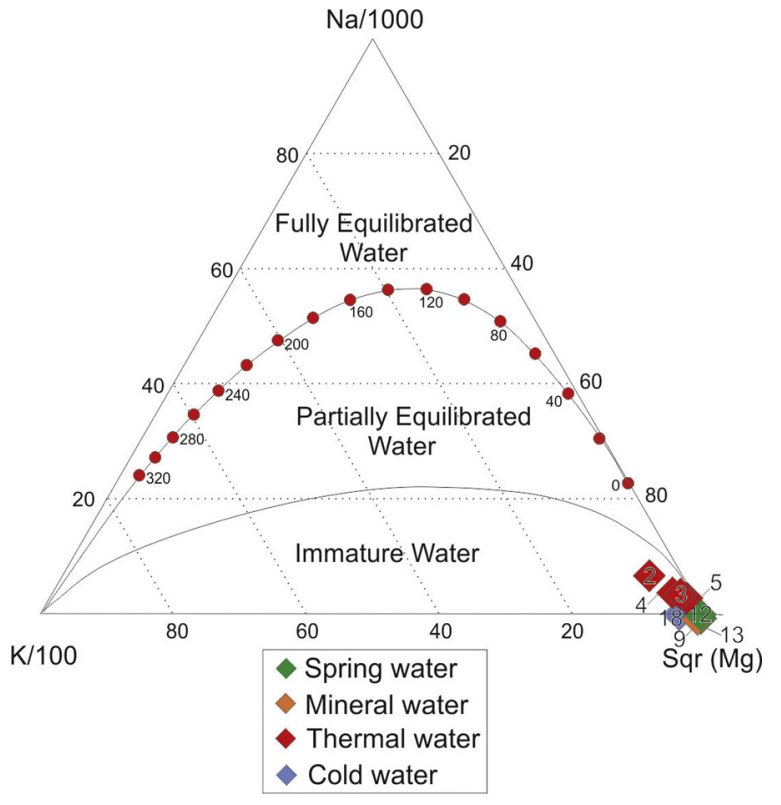

Fig. 9. Thermal waters on Na-K-Mg Triangle diagram for the study area.

Table 4

Reliable solute geothermometers results.

\begin{tabular}{llccccc}
\hline Geothermometers & Reference & 2 & ${ }^{*} 3$ & 4 & "5 & "8 \\
\hline Silica (ß-Cristobalite) & Fournier (1991) & 54 & 55 & 55 & 70 & 80 \\
Li-Mg & Kharaka and Mariner (1989) & 66 & 54 & 54 & 54 & 44 \\
\hline
\end{tabular}

* All calculated values are in ${ }^{\circ} \mathrm{C}$. 

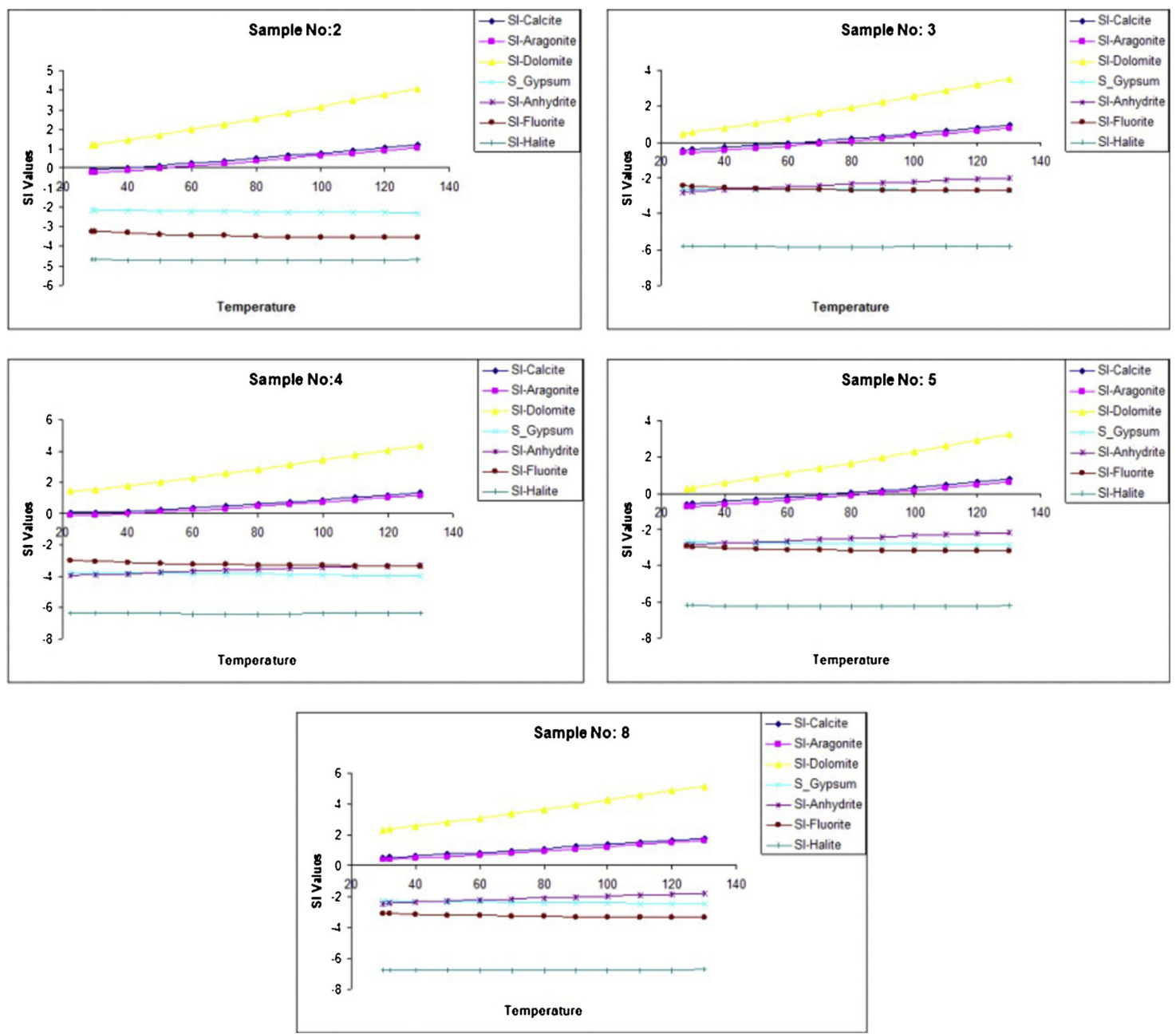

Fig. 10. Changes in the selected mineral saturations of thermal waters at different temperatures in the Varto Geothermal Region.

Giggenbach (1988) is a method to discriminate mature waters which have attained equilibrium with relevant hydrothermal minerals from immature waters and waters affected by mixing and/or re-equilibration at low temperatures during their circulation (Fig. 9). All samples plotted in the immature water zone in Fig. 9. Reservoir temperature values estimated by this method are invalid because thermal waters mix with some proportions of both cold and mineral waters. Na-K geothermometers thus provide unacceptable results for groundwater samples from this site.

A different approach to geothermometry (Reed and Spycher, 1984) is illustrated in Fig. 10, where SI (Saturation Indices) are computed as a function of temperature. In the calculation of the mineral saturation indices, the PhreeqC code (Parkhurst and Appelo, 1999) was used. It is easy to note that thermal waters are saturated with respect to dolomite, calcite and aragonite between $50{ }^{\circ} \mathrm{C}$ and $80^{\circ} \mathrm{C}$, thus suggesting this range of temperature as reliable for the deep geothermal reservoir temperature (Baba et al., 2010).

\subsection{Thermal numerical modeling setup}

In order to investigate magma heat transfer and fluid circulation a series of models is created that replicate the heat from a crustal shallow magma chamber which is overlain by a series of faults. The geometry of the models is based, as closely as possible, on the geology of the region. The various mechanical properties that are input into the models are investigated to obtain the most realistic outputs in terms of surface water temperatures. In the first set of models, shown in Fig. 11, vertical fault zones are simulated, each with a different permeability (k). The fault connects a magma chamber with an internal temperature of $900{ }^{\circ} \mathrm{C}$ to the surface, the geometry of the magma chamber is not generated and so we simply assign a 'hot' boundary. The surface temperature in this model is defined as with atmospheric conditions and so is $25^{\circ} \mathrm{C}$. The bottom of the model is defined with magma chamber conditions and so the given pressure and temperature conditions in this area are $10 \mathrm{MPa}$ and $900^{\circ} \mathrm{C}$ respectively, based on an intermediate magma composition (Murase and McBirney, 1973). The lower boundary is fixed, and both the left and right boundaries have no additional load but they are allowed to deform. The upper boundary is a free surface (a region free from shear stress). We present four models of this type (Fig. 11 a,b,c and d) to show the effect of permeability which varies across a narrow range (from $1 \times 10^{-15}$ in part a to $4.3 \times 10^{-15}$ in part d) of fluid velocities. Fluid rises in this model as we impose a temperature gradient of $25^{\circ} \mathrm{C} / \mathrm{km}$. As such the body temperature in the model varies over distance according to the equation $\mathrm{T}=(\mathrm{D} \cdot \mathrm{x})+25$.

In Fig. 12 we extend the results from Fig. 11 to investigate the effects of both fault width and fault permeability on heat transfer within the fault. In total we present 18 models, with six different permeabilities $\left(1.0 \times 10^{-15} \mathrm{~m}^{2}-4.3 \times 10^{-15} \mathrm{~m}^{2}\right)$ and three different fault widths $(1 \mathrm{~m}, 5 \mathrm{~m}$ and $10 \mathrm{~m})$. The models are designed with permeability steps of $0.1 \times 10^{-15} \mathrm{~m}^{2}$ and fault width steps of $0.1 \mathrm{~m}$ between the minimum and maximum ranges. In total, 430 different permeabilities over 100 different fault widths were investigated, here we present 18 representative model results from the full suite of model runs. We run the models to obtain a surface temperature of around $50{ }^{\circ} \mathrm{C}$ so as to 

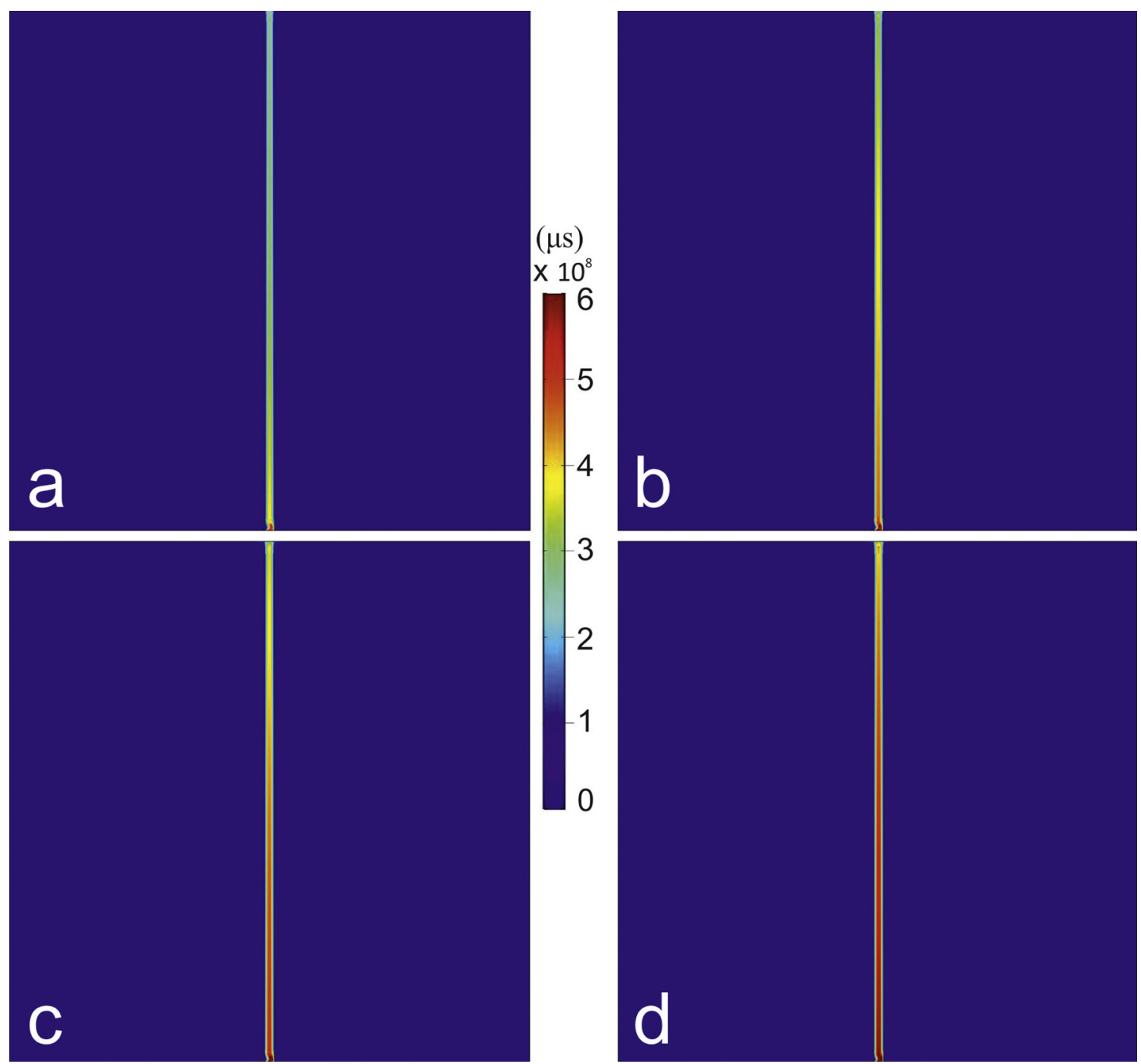

3

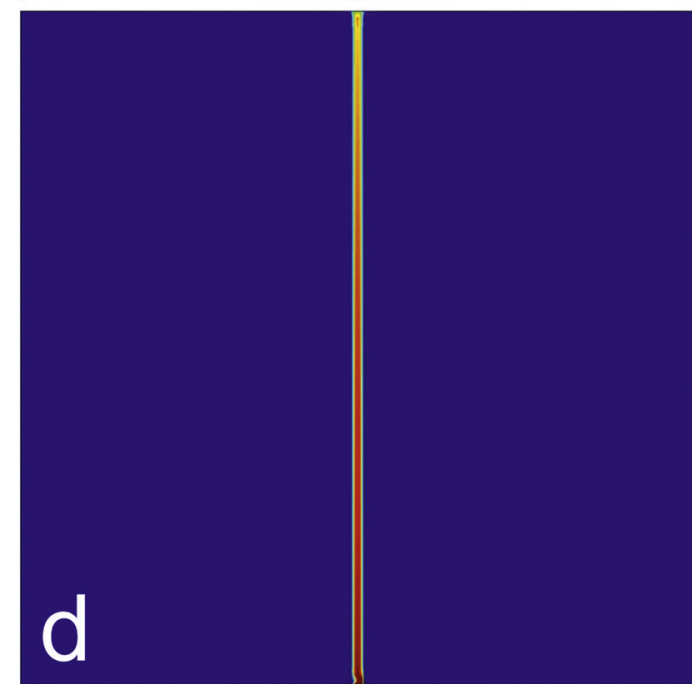

Fig. 11. Fluid velocities as a function of permeability change. The fault in a) has a permeability of $1.0 \times 10^{-15} \mathrm{~m}^{2}$ in part b) has a permeability of $2.1 \times 10^{-15} \mathrm{~m}^{2}$, in part c) has a permeability of $3.2 \times 10^{-15} \mathrm{~m}^{2}$ and in part d) has a permeability of $4.3 \times 10^{-15} \mathrm{~m}^{2}$. In the model we also impose a temperature gradient from $900^{\circ} \mathrm{C}$ at the base of the model to $25^{\circ} \mathrm{C}$ at the surface. The maximum velocity field is found in the fault with the largest permeability as expected.

compare with the field results.

In Fig. 13 we present a series of linear elastic stress models. These models consider the effects of regional tectonic loading on the fault zones of the KTJ. We imported a surface plan view of the faults from geological maps (Karaoğlu et al., 2016) (Fig. 12a), and then assigned a boundary horizontal extension (Fig. 13b) or compression (Fig. 13c) of $5 \mathrm{MPa}$. The resulting models (Figs. 13b and 13c) show the concentration and linkage of tensile stresses around the faults.

In the next set of models (Figs. 14,15) we use the results from the baseline models presented in Figs. 11-12 and combine these with the geological setting of the Karliova region (Fig. 13). The faults in plan view (Fig. 13) are extrapolated throughout the crust based on a contant dip, and interactions are inferred (Karaoğlu et al., 2016). The boundary conditions in Fig. 15 are fixed with a constraint on the horizontal edges, a set pressure and temperature on the lower boundary and a free surface on the upper boundary. The deepest fault inferred is around $10 \mathrm{~km}$, and so we set a pressure gradient of $10 \mathrm{MPa} / \mathrm{km}$, and a temperature gradient of $25^{\circ} \mathrm{C} / \mathrm{km}$. A porous medium with a very low permeability was defined as the host rock in order to prevent fluid leakage from the fault to the host rock. The system cannot model fluid losses and so heat transfer takes place only from the fluid to the solid. This happens while the fluid is passing within the fault as the model edges are fixed for any $\mathrm{Y}$ direction movements. For this reason, this model will not be affected by the fault zone to the right or left side of the model or by any effect from these two sides of the medium.

In Fig. 15, we plot the fluid velocity field in several orientations although the fracture network that creates the permeability is assumed to be isotropic. This is a limitation that we seek to investigate further in the future as it is well known that fault zones in complex tectonic regimes may be overprinted with anisotropic fracture networks (e.g., Browning et al., 2018).

\section{Results}

\subsection{Fluid and solid interactions}

In order to better understand fluid and heat transport throughout crustal structures such as permeable faults, we created models to investigate the effects of fluid and heat transfer (Figs. 11 and 12). In Fig. 11 we show how fluid velocity changes within the fault zones as a function of permeability. These models represent fluid at pressures of $10 \mathrm{MPa}$ injected into the fault (Fig. 11). The fault zone has a fixed size but the permeability varies by a factor of four. Permeability values are $1 \times 10^{-15} \mathrm{~m}^{2}$ to $4.3 \times 10^{-15} \mathrm{~m}^{2}$. In all the models the fastest velocities are found in the centre of the fault (assuming a homogenous fracture network), simulating a Poisuelle like flow. In the faults with the lowest 

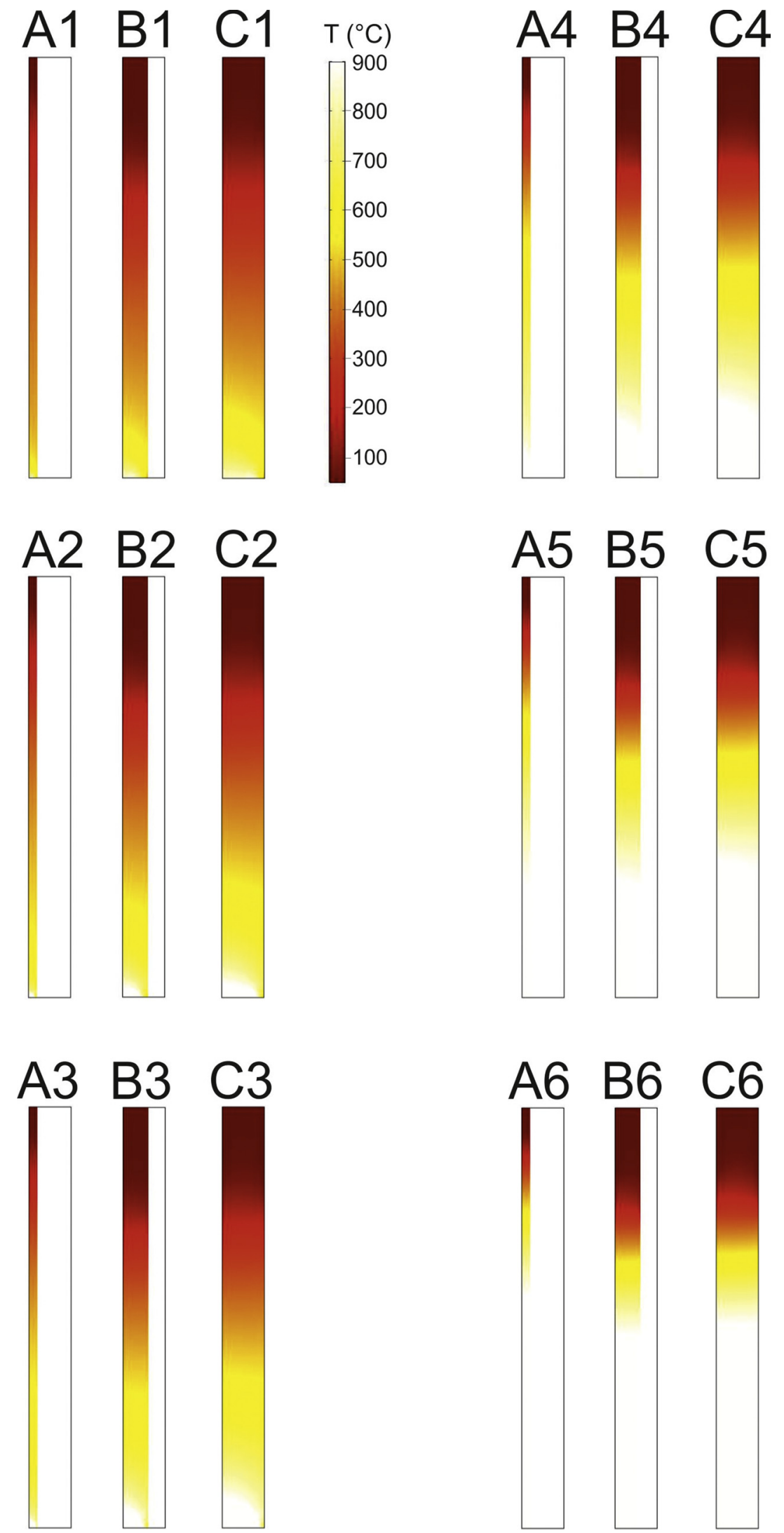

Fig. 12. Fluid heat loss in the modelled fault as a function of fault width (L), and permeability (k). The three different fault widths shown are $1 \mathrm{~m}, 5 \mathrm{~m}$ and $10 \mathrm{~m}$. The six different permeabilities (k) shown are 1) $1.0 \times 10^{-15} \mathrm{~m}^{2}$, 2) $1.5 \times 10^{-15} \mathrm{~m}^{2}$, 3) $\left.\left.2.1 \times 10^{-15} \mathrm{~m}^{2} 4\right) 2.7 \times 10^{-15} \mathrm{~m}^{2}, 5\right) 3.2 \times 10^{-15} \mathrm{~m}^{2}$, and 6) $4.3 \times 10^{-15} \mathrm{~m}^{2}$. 


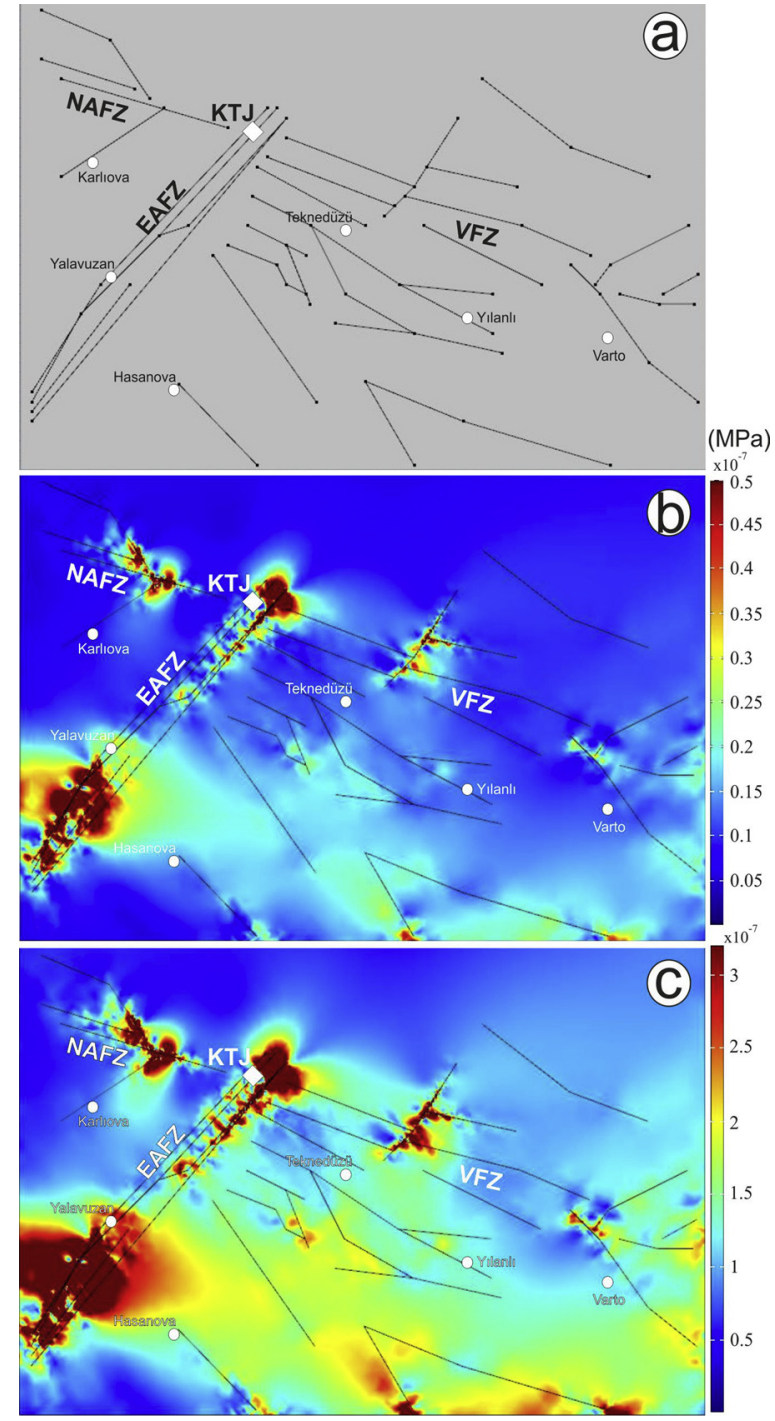

Fig. 13. a) Surface view of the model setup where the lineations simulate faults based on the geological setting along the Karlıova Triple Junction region. The only loading in these models is regional horizontal extension or compression. b) Modelled minimum principal compressive stresses induced from regional horizontal extension of $5 \mathrm{MPa}$. c) Modelled minimum principal compressive stresses induced regional horizontal compression of $5 \mathrm{MPa}$. NAFZ: North Anatolian Fault Zone, EAFZ: East Anatolian Fault Zone, VFZ: Varto Fault Zone, KTJ: Karlıova Triple Junction.

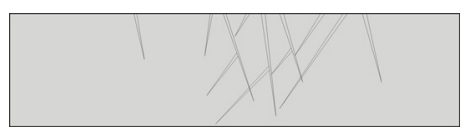

Fig. 14. A two dimensional vertical cross-section through a N-S striking profile of the faulted region around Varto caldera. The fault geometry is used as the model setup where each fault is assigned a different permeability. In all cases the top surface is unconstrained, whereas the $\mathrm{x}$ and lower $\mathrm{y}$ boundaries are fixed. The lower boundary of the model is assigned a starting temperature of $900{ }^{\circ} \mathrm{C}$ and the upper surface (free surface) is set at an atmospheric temperature of $25^{\circ} \mathrm{C}$.

permeabilities (Fig. 11a and b) the initial fluid velocity decreases almost immediately after fluid injection and is sustained for a maximum of $40 \%$ of the fault length. However, when the permeability is increased (even if only by a factor of 4) the initial injection fluid velocity is sustained for almost the entire length of the fault (Fig. 11c and d).

The rate at which fluids can pass through the fault network obviously has impllications for how quickly heat within the fluid and/ or gas is transferred to the surrounding rocks. Essentially when a fluid or a gas is flowing with a high velocity, there will be less interactions with the rock body so less heat is transferred to the porous medium. In Fig. 12 we consider this problem by presenting models that investigate how the temperature of the fluid with an initial magma temperature of $900{ }^{\circ} \mathrm{C}$ interacts with the body (crustal rocks) while it moves vertically through the fault to the surface (Fig. 12). Over the $10 \mathrm{~km}$ of the fault the fluid loses almost allit's heat, around $875^{\circ} \mathrm{C}$ depending on the permeability of the fault. We find, in all cases, that fault width has little effect in changing the temperature distribution. It is clear that the hot zone in part A5 (Fig. 12) is 4 times higher than A1 (Fig. 12). In A1 (Fig. 12), the temperature decreases rapidly to $700{ }^{\circ} \mathrm{C}$ (within a few tens of metres). In Fig. 12, part A6, the fluid remains with a temperature of $900{ }^{\circ} \mathrm{C}$ for almost $50 \%$ of the fault length. The body (crust) of the model medium uses the elastic parameters of Young Modulus (E) $40 \mathrm{GPa}$, Poisson's ratio 0.25 and a density of $3300 \mathrm{~kg} / \mathrm{m}^{3}$. The fluid thermal conductivity is $6[\mathrm{~W} /(\mathrm{m} * \mathrm{~K})]$, the fluid ratio of specific heat is 1 , and the fluid heat capacity at constant pressure is $4200[\mathrm{~J} /(\mathrm{kg} * \mathrm{~K})]$. The heat transfer coefficient, heat convection and heat conduction will all affect the fluid flow in the fault.

Both these models show that the properties of the material within the fault and their respective damage characteristics have significant effects on controlling the movement of both fluid and heat.

\subsection{Stress intensity around the Karlova triple junction}

In order to better understand the mechanical relations between stress intensity and thermal fluid discharge to the surface, a series of stress models were created (Fig. 13). These models are very important in terms of identifying the location of thermal fluid outflow points as tensile stress intensity may indicate areas of fracture and fault dilation and hence increased permeability. The stress concentration models show that the main faults (e.g. NAF, EAF and VFZ) are zones of maximum stress concentration and are thereby likely to control the majority of fluid flow within the region (Fig. 13). During periods of regional extension associated to extrusion of the Anatolian plate we find that the main result is that a NE-SW strike is dominant for the main crustal strain deformation (e.g., Karaoğlu et al., 2017, Fig. 3 and b). During periods of regional compression we find a $\mathrm{N}-\mathrm{S}$ compressional deformation is the main driving deformation process in the Karlova Triple Junction (e.g., Karaoğlu et al., 2017, Fig. 3 and c).

\subsection{Fluid circulation models in the KTJ}

To investigate fluid circulation throughout the upper crust for the specific case of the KTJ, some additional models were developed (based on heat transfer and velocity considering the geological setting around the KTJ, Figs. 14 and 15). In this model, velocity changes were observed in the fault zone based on permeability changes. The velocity changes in each fault show how it is possible to have fluid flowing inside that fault. It is very important to determine why hot fluid concentrates in some areas and not in others. Rivers are fed by both hot and cold waters sourced from underground but the situation is even more complex as some of the rivers are relatively close to each other. This is one of the challenges that we attempt to deal with using geomechanical rationale which highlights why both hot and cold fluids can form over very narrow areas (Fig. 2). The origin of hot waters can then be discussed but for this discussion it is necessary to return and use model setups from the model series A-C (A1-6) (Fig. 12).

In Fig. 15 we present the pressure changes within the faults (Fig. 15 A1-B1), the resulting fluid velocities (Fig. 15 A2-B4), and the temperature field (Fig. 15 A5-B5). In Fig. 15 A1-B1 we note that pressure concentrations around the faults increase from this deformative fault zone at outer province. This pressure value reaches to $6 \mathrm{MPa}$ through the upper crust where the western part of the KTJ is (Fig. 13 A1-B1). 

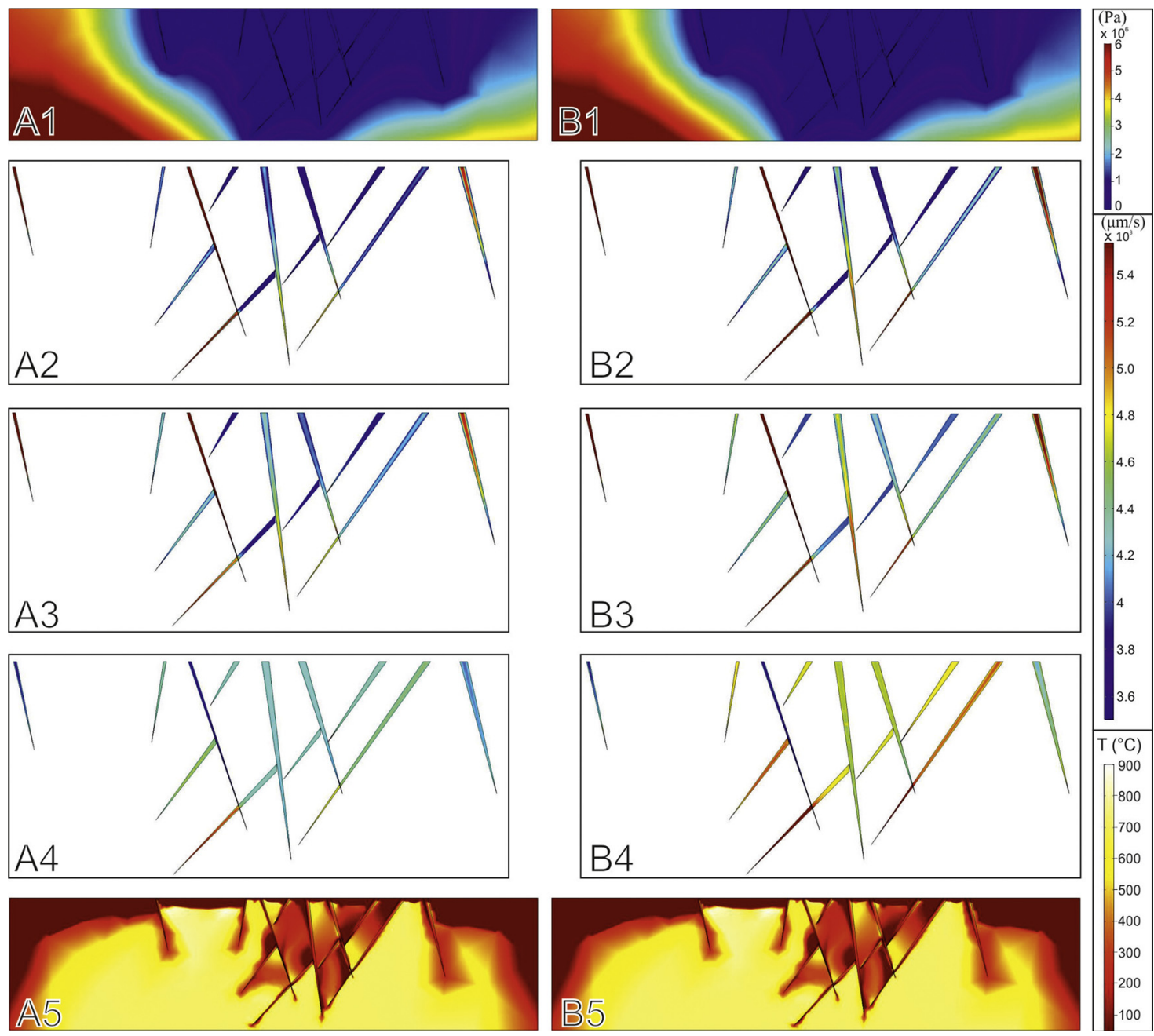

Fig. 15. Fluid circulation in the fault zones around the Karlıova region. A1) regional pressure at permeability $1 \times 10^{-15} \mathrm{~m}^{2}$, B1) regional pressure at permeability $4.3 \times 10^{-15} \mathrm{~m}^{2}$, A2) Fluid velocity within a fault of permeability $1 \times 10^{-15} \mathrm{~m}^{2}$, B2) Fluid velocity within a fault of permeability $4.3 \times 10^{-15} \mathrm{~m}^{2}$, displaying the total velocity field in both cases. A3) Fluid velocity within a fault of permeability $1 \times 10^{-15} \mathrm{~m}^{2}$, B3) Fluid velocity within a fault of permeability $4.3 \times 10^{-15} \mathrm{~m}^{2}$, displaying only the $\mathrm{x}$ direction (horizontal) flow in both cases. A4) fluid velocity within a fault of $1 \times 10^{-15} \mathrm{~m}^{2}$, B4) fluid velocity within a fault of permeability $4.3 \times 10^{-15} \mathrm{~m}^{2}$, displaying only the fluid velocity in the y direction (vertical) in both cases. A5) temperature field at permeability of $1 \times 10^{-15} \mathrm{~m}^{2}$, B5) temperature field at permeability of $4.3 \times 10^{-15} \mathrm{~m}^{2}$.

The minimum pressure value of $1 \mathrm{MPa}$ (maximum) is characteristic for the fault zone (Fig. 13 A1-B1).

In Fig. 15 A2-B4 we compare the effects of different permability values on fluid velocity. The main finding is that increasing the permeability increases the fluid velocity at faults (Fig. 15 B2-B4). Applying a value of the $4.3 \times 10^{-15} \mathrm{~m}^{2}$ rather than $1 \times 10^{-15} \mathrm{~m}^{2}$, which is in the total velocity field, clearly demonstrates the effect of the fluid velocity within these faults. We note that a fault placed at the eastern side of the section show a value from 5.0 to $5.6 \times 10^{3} \mu \mathrm{m} / \mathrm{s}$ (Fig. 15 A2-B2). Such an effect can be observed in all faults (Fig. 15 A2-B2). In Fig. 15 A3-B5 in the E-W profile we apply vertical and horizontal fluid velocity cases. We note again that there is a substantial incremental change between vertical (Fig. 15 A3-B3) and horizontal cases (Fig. 15 A4-B4). While this fluid velocity value is around $5.4 \times 10^{3} \mu \mathrm{m} / \mathrm{s}$ (Fig. $15 \mathrm{~B} 3$ ), the values around $4.4 \times 10^{3} \mu \mathrm{m} / \mathrm{s}$ (Fig. $15 \mathrm{~B} 4$ ).

Our numerical model indicate that the temperature field show markedly greater values around the fault zone (Fig. 15 A5-B5). These value reach to $900{ }^{\circ} \mathrm{C}$ particularly in the deeper zone, whilst the temperature show a decrease (between $100-300^{\circ} \mathrm{C}$ ) where the cross faults interact to each other (Fig. 15 A5-B5). We note that there is no substantial effect of the changing of permability values on temperature field (Fig. 15 A5-B5).
In this model, it can be observed that pressure is relatively constant at different permeabilities and so the temperature does not change dramatically. The temperature inside the fault zone changes similar to the model in Fig. 15 (A5 and B5). The model also displays how permeability in the fault zone affects fluid circulation, while there is no substantial impact on the solid porous matrix.

\section{Discussion and conclusions}

Kinematic data is a very useful tool to better understand the episodic deformational fields and fluid circulation interactions throughout the crust underneath the KTJ region (Fig. 3). Field studies coordinated with kinematic data show that the complexity of these fault deformations indicate variations in the local stress field following initial activity of a westward extrusion of the Anatolian plate since $6 \mathrm{Ma}$. The direction of the compressive principal stress $\left(\sigma_{1}\right)$ has been shifted during this deformational period. This direction and local stress fields imply major controls of both magmatic fluids on magma propagation as an individual volcano, or fluid circulation throughout the crust in the region (Fig. 3).

Since Late Miocene, deformation of the KTJ has been controlled by the combined effects of continuing compressional tectonics due to a 
regional shortening of Eastern Anatolia. This shortening is represented by a local stress field, and the westward displacement of Anatolia, which has kinematically responded through a local extensional stress field and coincides with transtensional tectonics (Fig. 3). In this framework, a successive and reactive tectonic motion has caused the incremental complex movement of numerous fault blocks which have resulted in mostly non-thermal but rarely thermal fluid circulation within intensely-deformed crustal materials. This is illustrated by the local stress fields and thermal and non-thermal spring points (Fig. 3). We note that non-thermal fluids are likely concentrated around zones of high minimum principal compressive (maximum tensile) stress $\left(\sigma_{3}\right)$ (Fig. 3). Although these zones are expected as sources for thermal waters, the non-thermal waters like thermal waters tend to also circulate within the upper crust. These non-thermal waters may therefore be circulating in open fractures and faults in the upper level of the crust, but have not yet been subject to heating processes. Thus, these nonthermal waters may be temporally younger than other thermal water sources.

The fault stations of F3, 5, 8, 11, 15 and 16 show that an extensional regime agrees well with the location of non-thermal waters (Fig. 3). However, both non-thermal and thermal waters are found to circulate not only in extensional but also in compressional regimes (Fig. 3). So, the combined field and numerical studies show that crustal heterogeneity in the form of faults, as well as fault attitude and mechanical properties of both the crust and crustal faults, below the KTJ encourage fluid circulation in the region.

Field data and results from a suite of numerical modeling tests indicate that thermal water transport is influenced by the depth of intruded magmas and the permeability of crustal faults in the upper crust.

Magma chamber location plays a prominent role in the surface discharge of hot water around the Varto region (Fig. 1b). The thermal water discharge points are located just between the Varto caldera to the north, and the Özenç volcano to the east (Fig. 2). Numerical models indicate that maximum tensile and shear stresses concentrate at the lateral margins of magma chambers and at the Earth's surface above the magma chamber (see Karaoğlu et al., 2016). These stress accumulation zones are directly associated with thermal water circulation through the crust (Fig. 13). So, these thermal water locations in the region might be related to this stress intensity and fluid interaction. In volcanoes worldwide, the thermal water cycle might be used to indicate the lateral margins of magma chambers as zones of increased faulting and fracturing.

Hydrogeochemistry of the samples indicates that thermal water springs are likely heated by steam. Field studies, hydrogeochemical data and numerical models suggest that the magma systems beneath both the Varto caldera and the Özenç volcanoes are the main heat source for thermal water in the Varto region.

The results reveal that most water in the study area comes from the outcropping volcanic rocks in the Varto Region. The rocks demonstrate typical characteristics of water resources which originate in highly fractured volcanic formations where water seeps through cracks and faults and flows to the surface at lower elevations. On the basis of major ion chemistry, the Piper and Schoeller diagrams (Fig. 4) show that the majority of the cold water resources are of the $\mathrm{Ca}-\mathrm{HCO}_{3}$ type and the thermal water of the $\mathrm{Na}-\mathrm{HCO}_{3}-\mathrm{Cl}$ type. As the fractures allow a deep circulation of groundwater and a dominant NA-Cl component, we infer that the waters have a volcanic origin. However, the hot waters have the same recharge area as the cold waters. Reliable reservoir temperature ranges for hot waters were obtained with $\mathrm{Li}-\mathrm{Mg}$ and $\beta$-Cristobalite geothermometers as $44-66^{\circ} \mathrm{C}$ and $54-80^{\circ} \mathrm{C}$, respectively. These values were also checked with Saturation Indices (SI) vs T diagrams. Results of SI vs $\mathrm{T}$ diagrams indicate equilibration with calcite and aragonite. The result shows that jointed volcanic rocks are a reservoir for the geothermal system and that the heat source for the geothermal fluid is the magma chamber.

Fluid and solid interactions and fluid circulation models show the role of fault permeability on heat loss during fluid circulation. Also Fig. 12 illustrates what happens to fluid heat loss when the fault permeability and fault width changes. The main boundary condition is the constant injection pressure of $10 \mathrm{MPa}$. As the pressure is constant and dependent on the injecting boundary, fault width has no obvious effect. The permeability ranged from $1 \times 10^{-15}$ to $4.3 \times 10^{-15} \mathrm{~m}^{2}$. When the fault permeability increases, heat loss from $900{ }^{\circ} \mathrm{C}$ to $50^{\circ} \mathrm{C}$ takes place over a longer distance. In Fig. 15, the model is a combination of two previous models. The same effect of changing permeability of the fault was investigated in a porous medium. The model illustrated that increasing permeability from $1 \times 10^{-15}$ to $4.3 \times 10^{-15} \mathrm{~m}^{2}$ can significantly affect the fluid pressure drop. Fluid injected at pressure declines from $10 \mathrm{MPa}$ to atmospheric pressure over a smaller distance when the permeability is very low. The additional physical parameters added to Fig. 15 is the porous medium body temperature, and also the effects of stress and strain on fluid circulation in the porous medium where observed. These effects usually have little or no impact. However, those effects are very substantial and visible near the boundary area of the fault zone and the porous medium. In these models the detailed structural geology and fault zone are presented to illustrate how a relatively small permeability variation from $1 \times 10^{-15}$ to $4.3 \times 10^{-15} \mathrm{~m}^{2}$ can significantly affect fluid circulation in fault zones. The result is important as the permeability of fault zones can be heterogeneous (Mitchell and Faulkner, 2009) and so for a proper understanding of geothermal resources and hot water fluid circulation this must be considered.

\section{Acknowledgements}

This study was supported by funds from Eskisehir Osmangazi Üniversitesi (Project Numbers: 201715031 and 201715A215). Özgür Karaoğlu was supported by The Scientific and Technological Research Council of Turkey (TÜBİTAK) International Postdoctoral Research Fellowship Programme. Mohsen Bazargan was supported by Weld On Sweden for European Doctoral research programme. We are grateful to the editor Eva Schill and three anonymous reviewers, for comments which improved this work.

\section{Appendix A. Supplementary data}

Supplementary material related to this article can be found, in the online version, at doi:https://doi.org/10.1016/j.geothermics.2019.05. 003.

\section{References}

Ambraseys, N., Zatopek, A., 1968. The Varto Ustukran earthquake of 19 August 1966. B. Seismol. Soc. Am. 58, 47-102.

Armijo, R., Meyer, B., Hubert-Ferrari, A., Barka, A.A., 1999. Propagation of the North Anatolian fault into the Northern Aegean: timing and kinematics. Geology 27, $267-270$.

Attendorn, H.G., Bowen, R., 1997. Radioactive and Stable Isotope Geology. Chapman and Hall, London, pp. 519.

Baba, A., Yiğitbaş, E., Ertekin, C., 2010. Hydrogeochemistry of geothermal resources of eastern part of turkey: a case study, Varto Region. World Geothermal Congress $20101-8$.

Baker, E., 1995. Characteristics of hydrothermal discharge following a magmatic intrusion. Geol. Soc. (Lond.) Spec. Publ. 87, 65-76.

Baker, E.T., Urabe, T., 1996. Extensive distribution of hydrothermal plumes along the superfast spreading East Pacific Rise, 13 30'-18 40’ S. J. Geophys. Res-Sol. EA 101 (B4), 8685-8695.

Barka, A.A., 1992. The North Anatolian fault zone. Ann. Tecton. 6, 164-195.

Bozkurt, E., 2001. Neotectonics of Turkey-a synthesis. Geodin. Acta 14, 3-30.

Browning, J., Meredith, P.G., Stuart, C., Harland, S., Healy, D., Mitchell, T.M., 2018. A directional crack damage memory effect in Sandstone under true triaxial loading. Geophys. Res. Lett. 45, 6878-6886.

Buket, E., Temel, A., 1998. Major-element, trace element, and Sr-Nd isotopic geochemistry and genesis of Varto (Muş) volcanic rocks, Eastern Turkey. J. Volcanol. Geotherm. Res. 85, 405-422.

Caracausi, A., Ditta, M., Italiano, F., Longo, M., Nuccio, P.M., Paonita, A., Rizzo, A., 2005. Changes in fluid geochemistry and physico-chemical conditions of geothermal 
systems caused by magmatic input: The recent abrupt outgassing off the island of Panarea (Aeolian Islands, Italy). Geochim. Cosmochim. Ac. 69 (12), 3045-3059.

Cherubini, C., Giasi, C.I., Pastore, N., 2013. Evidence of non-Darcy flow and non-Fickian transport in fractured media at laboratory scale. Hydrol. Earth Syst. Sci. 17 (7), 2599-2611.

Craig, H., 1961. Isotopic variations in meteoric waters. Science 133, 1702-1703.

Deutsch, W., Siegel, R., 1997. Groundwater Geochemistry: Fundamentals and Applications to Contamination. Lewis Publishers, New York.

Durbin, A., 1986. On the k- $\varepsilon$ stagnation point anomality. Int. J. Heat Fluid Flow 17, 89-90.

Eisenlohr, T., 1995. Die Thermalwässer der Armutlu-Halbinsel (NW-Türkei) und deren Beziehung zu Geologie und Aktiver Tektonik, PhD. Dissertation, ETH-Zürich, Nr.11340.

Fournier, R.O., 1991. Water geothermometers applied to geothermal energy. In: D’Amore, F. (Ed.), Application of Geochemistry in Geothermal Reservoir Development. UNITAR, Rome, Italy, pp. 37-65.

Furlong, K.P., Schwartz, S.Y., 2004. Influence of the Mendocino triple junction on the tectonics of coastal California. Annu. Rev. Earth Planet. Sci. 32, 403-433.

Gat, J.R., 1983. Precipitation, groundwater and surface waters: control of climate parameters on their isotopic composition and their utilisation as palaeo climatological tools. Proceedings, Palaeoclimates and Palaeowaters: A Collection of Environmental Isotope Studies (Proc. Advisory Group Mtg Vienna, 1980) 3-12.

Giggenbach, W.F., 1988. Geothermal Solute Equilibria. Derivation of Na-K-Mg-Ca Geoindicators. Geochim. Cosmochim. Ac. 52, 2749-2765.

Giggenbach, W.F., 1996. Chemical Composition of Volcanic Gases. In Monitoring and Mitigation of Volcano Hazards. Springer, Berlin Heidelberg, pp. 221-256.

Herece, E., 2008. Atlas of East Anatolian Fault. General Directorate of Mineral Research and Exploration. Special Publication Series, Ankara, Turkey.

Hubert-Ferrari, A., King, G., van der Woerd, J., Villa, I., Altunel, E., Armijo, R., 2009. Long-term evolution of the North Anatolian Fault: new constraints from its eastern termination. In: van Hinsbergen, D.J.J., Edwards, M.A., Govers, R. (Eds.), Collision and Collapse at the Africa-Arabia-Eurasia Subduction Zone, pp. 133-154 Geol. Soc. Spec. Publ. 311.

Isik, V., Uysal, I.T., Caglayan, A., Seyitoglu, G., 2014. The evolution of intraplate fault systems in central Turkey: Structural evidence and Ar-Ar and Rb-Sr age constraints for the Savcili Fault Zone. Tectonics 33 (10), 1875-1899.

Italiano, F., Sasmaz, A., Yuce, G., Okan, O.O., 2013. Thermal fluids along the East Anatolian Fault Zone (EAFZ): geochemical features and relationships with the tectonic setting. Chem. Geol. 339, 103-114.

Karaoğlu, Ö., Browning, J., Bazargan, M., Gudmundsson, A., 2016. Numerical modelling of triple-junction tectonics at Karlıova, Eastern Turkey, with implications for regional magma transport. Earth Planet. Sc. Lett. 452, 152-170.

Karaoğlu, Ö., Sağlam-Selçuk, A., Gudmundsson, A., 2017. Tectonic controls on the Karlıova Triple Junction (Turkey): implications for tectonic inversion and the initiation of volcanism. Tectonophysics 694, 368-384.

Karaoğlu, Ö., Browning, J., Salah, M.K., Elshaafi, A., Gudmundsson, A., 2018. Depths of magma chambers at three volcanic provinces in the Karliova region of Eastern Turkey. B.Volcanol. 80 (9), 69.
Kaufmann, S., Libby, W.F., 1954. The natural distribution of tritium. Phys. Rev. 93 (6), 1337-1344.

Kazemi, G.A., Lehr, J.H., Perrochet, P., 2006. Groundwater Age. Wiley-Interscience, New Jersey, USA.

Kharaka, Y.K., Mariner, R.H., 1989. Chemical geothermometers and their application to formation waters from sedimentary basins. In: Naeser, N.D., McCulloh, T.H. (Eds.), Thermal History of Sedimentary Basins. Springer-Verlag, New York, NY, USA, pp. 99-117.

Kresic, N., 2007. Hydrogeology and Groundwater Modeling, $2^{\text {nd }}$ edition. CRC Press, Taylor \& Francis Group, USA.

Mazor, E., 2004. Applied Chemical and Isotopic Groundwater Hydrology, $3^{\text {rd }}$ edition. Marcel Dekker, Inc, New York.

Mitchell, T.M., Faulkner, D.R., 2009. The nature and origin of off-fault damage surrounding strike-slip fault zones with a wide range of displacements: a field study from the Atacama fault system, northern Chile. J. Struct. Geol. 31 (8), 802-816.

Nicholson, K., 1993. Geothermal Fluids Chemistry and Exploration Techniques. SpringerVerlag, Berlin.

Okay, A.I., Tüysüz, O., 1999. Tethyan sutures of northern Turkey. Geol. Soc. Spec. Publ. $156,475-515$.

Parkhurst, D.L., Appelo, C.A.J., 1999. User's guide to PHREEQC (Version 2) -a computer program for speciation batch-reaction, one-dimensional transport, and inverse geochemical calculations. Pearce, J.A., Bender, J.F., De Long, S.E., Kidd, W.S.F., Low, P.J., Güner, Y., Saroglu, F., Yilmaz, Y., Moorbath, S., Mitchell, J.G., 1990. Genesis of collision volcanism in Eastern Anatolia, Turkey. J. Volcanol. Geotherm. Res. 44 189-229.

Poidevin, J.L., 1998. Provenance studies of obsidian artefacts in Anatolia using the fission track dating method, an overview. In: Gourgaud, A., Gratuze, B., Poupeau, G., Poidevin, J.L., Cauvin, M.C. (Eds.), L'Obsidienne au Proche et Moyen Orient, du Volcan a` l'Outil. BAR International Series Hadrian Books 738, pp. 105-156.

Press, F., Siever, R., 1995. Allgemeine Geologie. Spektrum Akademischer Verlag, Heidelberg Berlin, Oxford.

Reed, M., Spycher, N., 1984. Calculation of $\mathrm{pH}$ and mineral equilibria in hydrothermal waters with application to geothermometry and studies of boiling and dilution. Geochim. Cosmochim. Ac. 48, 1479-1492.

Salah, M.K., Sahin, S., Aydin, U., 2011. Seismic velocity and Poisson's ratio tomography of the crust beneath east Anatolia. J. Asian Earth Sci. 40, 746-761.

Sayın, M., Eyüpoğlu, S.Ö., 2005. Determination of the Local Meteoric Water Lines Using Stable Isotope Contents of Precipitation In Turkey (in Turkish). Proceedings, II. National Symposium of Isotopic Methods in Hydrology, General Directorate of State Hydraulic Works, İzmir. pp. 323-344.

Taler, J., Duda, P., 2006. Solving Direct and Inverse Heat Conduction Problems. Springer. Verhagen, B.T., Geyh, M.A., Fröhlich, K., With, K., 1991. Isotope hydrological methods for the quantitative evaluation of groundwater resources in arid and semi-arid areas. Research Reports of the Federal Ministry for Economic Cooperation of the Federal Republic of Germany, Bonn, Germany, 7-122.Versteeg, H.K., Malalasekera, W., 1995. An Introduction to Computational Fluid Dynamics. Prentice Hall 1995.

Wallace, R.E., 1968. Earthquake of August 19, 1966. Varto Area, Eastern Turkey. B. Seismol. Soc. Am. 58, 11-45. 